Check for updates

Cite this: RSC Adv., 2017, 7, 21093

Received 4th February 2017 Accepted 30th March 2017

DOI: $10.1039 / \mathrm{c} 7 \mathrm{ra01440f}$

rsc.li/rsc-advances

\section{Bioreducible amphiphilic block copolymers based on PCL and glycopolypeptide as multifunctional theranostic nanocarriers for drug delivery and MR imaging $\dagger$}

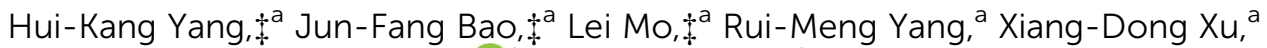 \\ Wen-Jie Tang, ${ }^{a}$ Jian-Tao Lin, (DD ${ }^{\mathrm{b}}$ Guan-Hai Wang, ${ }^{\mathrm{b}}$ Li-Ming Zhang ${ }^{\star \mathrm{c}}$ \\ and Xin-Qing Jiang (D) *a
}

Amphiphilic diblock poly( $\varepsilon$-caprolactone)-b-glycopolypeptides (PCL-SS-GPPs) bearing disulfide bonds were synthesized from a clickable poly( $\varepsilon$-caprolactone)-SS-poly(2-azidoethyl-L-glutamate) diblock copolymer. Galactosyl and lactosyl sugar units as targeting ligands were conjugated to the polypeptide blocks via an efficient click reaction. The chemical structures of PCL-SS-GPPs were characterized by Fourier transform infrared spectroscopy and nuclear magnetic resonance analysis. Owing to their amphiphilic nature, these copolymers could self-assemble into spherical nano-sized micelles in an aqueous medium, as confirmed by fluorometry, transmission electron microscopy, and dynamic light scattering. The hydrophobic anticancer drug doxorubicin (DOX) and superparamagnetic iron oxide (SPIO) nanoparticles (NPS), as the magnetic resonance imaging (MRI) contrast agent, were simultaneously encapsulated in the hydrophobic core of the micelles via dialysis. The release profiles of encapsulated DOX from the SPIO/DOX-loaded PCL-SS-GPPs micelles were shown to be rapid in the presence of $10 \mathrm{mM}$ glutathione (GSH) within $24 \mathrm{~h}$, whereas in the absence of GSH, there was less than $35 \%$ DOX released from the PCL-SS-GPPs micelles in $24 \mathrm{~h}$. Inverted fluorescence microscopy revealed the specific interaction between the sugars units on the PCL-SS-GPPs surface with the FITC-lectin. MTT assay demonstrated that the blank PCL-SS-GPPs micelles were nontoxic to the HepG2 cells, even for concentrations up to $500 \mu \mathrm{g} \mathrm{mL}^{-1}$, whereas the free DOX and DOX-loaded PCL-SS-GPPs micelles showed significant cytotoxicity against the HepG2 cells. The fluorescence images and flow cytometry tests revealed that DOX could be efficiently transported into HepG2 tumor cells by PCL-SS-GPPS micelles. The PCL-SS-GPPs micelles loaded with superparamagnetic iron oxide (SPIO) nanoparticles enabled excellent MRI contrast enhancement, thus confirming their effectiveness for MR imaging.

\section{Introduction}

Cancer remains a major threat to human health today and its treatment still faces serious challenges. ${ }^{1}$ Chemotherapy is one of the most common treatments for various human malignancies in oncology. However, the poor pharmacokinetics, lack of tumor

\footnotetext{
${ }^{a}$ Department of Radiology, Guangzhou First People's Hospital, Guangzhou Medical University, Guangzhou 510180, China.E-mail: gzcmmcjxq@163.com; 123086302@ qq.com; 605036656@qq.com; 2379828219@qq.com; yangrm0708@gmail.com; xxd2190@163.com; 770159633@qq.com

${ }^{b}$ Dongguan Scientific Research Center, Guangdong Medical University, Dongguan 523808, China. E-mail: linjt326@163.com; wanggh0101@163.com

'School of Materials Science and Engineering, Sun Yat-sen University, Guangzhou 510275, China. E-mail: ceszhlm@mail.sysu.edu.cn

$\dagger$ Electronic supplementary information (ESI) available. See DOI: 10.1039/c7ra01440f

\$ These authors contributed equally to this work.
}

selectivity, and dose-limiting toxicities of many anti-cancer drugs can directly cause many chemotherapeutic failures in patients with metastatic tumors. ${ }^{2,3}$ Currently, polymeric nanoparticles have been widely employed as drug delivery vehicles for cancer chemotherapy as they can effectively improve drug aqueous solubility, blood circulation time, and biodistribution..$^{4-6}$ However, the lack of specific tumor targetability and inefficient drug release usually lead to a modest therapeutic effect. ${ }^{7,8}$ To overcome these limitations, it is desirable to design multifunctional delivery systems that can achieve targeted delivery and triggered release of the payload under intracellular stimuli such as mildly acidic $\mathrm{pH}$, reductive agents, and enzymes, ${ }^{9-13}$ as well as the real-time monitoring of drug localization. ${ }^{9-13}$

Currently, theranostic nanocarriers have attracted significant interest due to the combination of therapeutic and diagnostic agents on a single platform. The theranostic 
nanocarriers can be equipped with a variety of functional agents including target ligands for precise cancer cell targeting, anticancer drugs for treatment, and diagnostic agents for the detection or even real-time monitoring of the therapeutic agents. After loading the therapeutic and diagnostic agents, the theranostic nanocarriers can achieve systemic circulation, evade host defenses, and deliver the drug and diagnostic agents at the targeted site for diagnosis and disease treatment at the cellular and molecular level. ${ }^{\mathbf{1 4 1 5}}$ Lee et al. prepared theranostic micelles containing the photosensitizing drug Ce6 for photodynamic tumor therapeutic treatment and found that iron oxide $\left(\mathrm{Fe}_{3} \mathrm{O}_{4}\right)$ offered high contrast magnetic resonance (MR) imaging of the tumor in vivo. ${ }^{\mathbf{1 6}}$ It has been reported that glutathione (GSH), a thiol-containing tripeptide capable of cleaving disulfide bonds by a redox reaction, is abundant in the cytoplasm of cells $(110 \mathrm{mM})$, whereas it is rarely present in blood plasma ( $2 \mathrm{mM})$. Reduction-sensitive nanocarriers have been developed for specific tumor targetability and can achieve the rapid release of encapsulated drugs inside the target cells or under reductive conditions, mimicking the intracellular compartments. ${ }^{17,18}$ As for target delivering, carbohydrates are widely used as targeting ligands owning to their special cell interaction and recognition. Galactosyl and lactosyl sugar units have the ability to recognize the asialoglycoprotein receptors (ASGP-R), which are overexpressed on hepatocellular carcinoma cells, due to their ability to bind lectins. ${ }^{\mathbf{1 9 , 2 0}}$ The interaction behavior between galactosyl and lactosyl sugar units with cell surface receptors make them attractive therapeutic and diagnostic targets. However, the interaction of these proteins with a carbohydrate is quite weak, so a multivalent effect of glycopolymers are widely used to enhance the biological binding or internalization. ${ }^{21}$ This phenomenon is often referred to as "the cluster glycoside effect", where the clustering of carbohydrates leads to high avidity receptor binding. ${ }^{22}$ As important analogs of natural glycoproteins, synthetic glycopolypeptides are regarded as new-generation drug carriers, owning to their biodegradability, well-defined secondary structures, and specific carbohydrate-protein interactions. $^{23-25}$ Normally, glycopolypeptides have been widely obtained by direct ring-opening polymerization (ROP) of the glycosylated $\alpha$-amino acid $N$-carboxyanhydride (NCA) monomers. ${ }^{26}$ However, it is still difficult to obtain the glycosylated NCA monomers with enough purity to allow their controlled polymerization. ${ }^{27}$ There has been tremendous interest and activity in recent years in the preparation of $\alpha$ amino acid NCA containing reactive functional groups, such as alkyne, azido, and alkene functional groups. ${ }^{2,28}$ These functional groups can undergo highly effective "click" types reactions, such as azide-alkyne cycloadditions, thiol-ene, and thiol-yne reactions, to prepare glycopolypeptides. ${ }^{29,30}$ Chen's lab reported three different azide-functionalized monosaccharides conjugated onto alkyne functional polypeptides using azide-alkyne cycloadditions. The resulting glycopolypeptides were water soluble and could bind with Con A lectin. ${ }^{31}$ Zhang et al. reported the synthesis of glycopolypeptides by the azido functional polypeptides reaction with alkyne-functionalized D-mannose using copper catalysis in
DMF. ${ }^{32}$ Schlaad et al. reported the synthesis of stimuliresponsive glycopolypeptides by the combination of the ROP with $\alpha$-amino NCA monomers and "thiol-ene" click reaction with thio-functionalized sugar. ${ }^{33}$ Lecommandoux et al. synthesized amphiphilic glycopeptides by the combination of the sequential ring-opening polymerization of $\alpha$-amino acid NCA monomers and a "click" reaction with azidefunctionalized sugar molecules. The amphiphilic glycopeptides self-assembled in water into spherical and worm-like micelles as well as polymersomes, which showed specific recognition/binding capability to glycosidase. ${ }^{34,35}$ Many existing amphiphilic glycopeptides are homopolypeptides, where the hydrophobic block originates from the polypeptide backbone. The incorporation of a nonpeptidic hydrophobic block would widen the scope of the resultant polymer properties. ${ }^{36}$ Gupta et al. synthesized biocompatible multi-arm star copolymers comprising a hydrophilic glycopolypeptide and hydrophobic poly(e-caprolactone) block using a ring-opening polymerization and click chemistry. The resulting noncytotoxic mannosylated rods and polymersomes could not only encapsulate hydrophobic and hydrophilic dyes within the nanostructures, but also displayed carbohydrate-specific uptake toward MDA-MB-231 cells. ${ }^{37}$ Recently, Cao et al. reported the synthesis of disulfide bonds linked to the amphiphilic glycopolypeptide analog poly(6-O-methacryloyl-Dgalactopyranose)-SS-poly( $\gamma$-benzyl-L-glutamate) (PMAgalaSS-PBLG). The hydrophilic block was a polymathacrylate derivative synthesized by RAFT polymerization in a controlled manner. The poly $(\gamma$-benzyl-L-glutamate) acted as a hydrophobic block. Nanoparticles obtained from the glycopolypeptide analogs self-assembly could act as multifunctional vehicles for protein recognition, drug delivery, and hepatoma cell targeting. ${ }^{38}$

Herein, we report the synthesis of reduction-sensitive amphiphilic PCL-SS-GPPs diblock copolymers as SPIO and DOX nanocarriers for controlled drug delivery and efficient MRI contrast enhancement. To the best of our knowledge, reductionresponsive micelles combining amphiphilic glycopolypeptide and poly( $\varepsilon$-caprolactone) constructed via click chemistry have not yet been extensively explored for theranostic applications. The PCL-SS-GPPs composed of a hydrophobic PCL block and hydrophilic glycopolypeptides were prepared via click chemistry, where poly( $\varepsilon$-caprolactone)-SS-poly(2-azidoethyl-L-glutamate) was covalently conjugated with alkyne galactosyl and lactosyl sugar units. The self-assembly behaviors of amphiphilic PCLSS-GPPs in solution were investigated using fluorescence spectroscopy, dynamic light scattering (DLS), and transmission electron microscopy (TEM). As shown in Scheme 1, the introduction of disulfide bonds was expected to adjust the release of DOX, due to the reduction-responsive disassembling behaviors of the micelles. Their lectin-recognition properties, intracellular drug delivery, and growth inhibition to HepG2 cells were investigated via fluorescence microscopy, MTT, and flow cytometry assay. Furthermore, the magnetic properties of the micelles containing SPIO were characterized to understand their efficacy as MRI probes. 


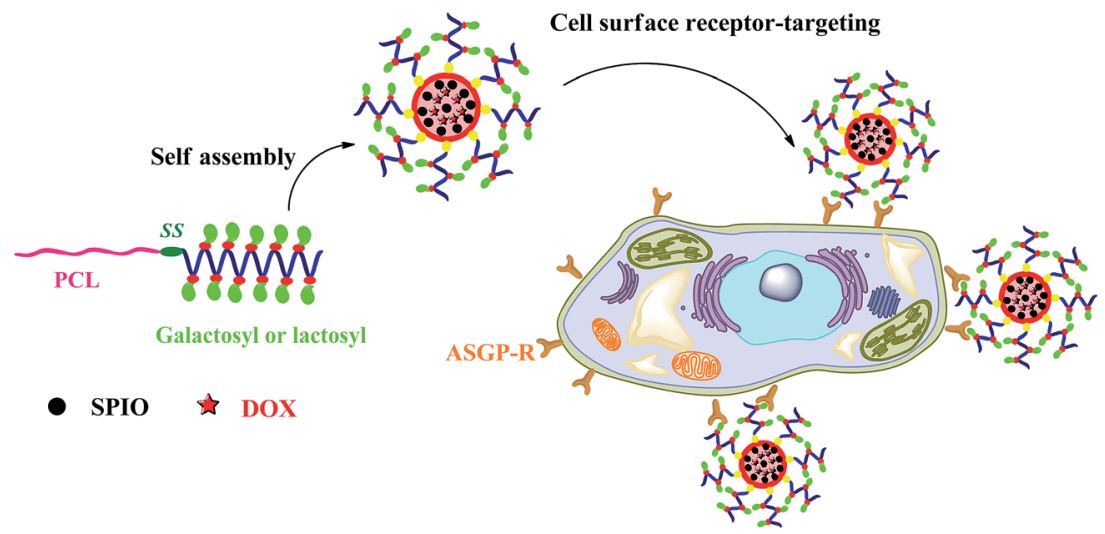

Scheme 1 Schematic of the reduction-responsive PCL-SS-GPPs micelles as nanocarriers for cancer chemotherapy and imaging.

\section{Experimental}

\subsection{Materials}

Copper sulfate $\left(\mathrm{CuSO}_{4} \cdot 5 \mathrm{H}_{2} \mathrm{O}\right)$, tin(II) 2-ethylhexanoate $\left(\mathrm{Sn}(\mathrm{Oct})_{2}\right.$, 95\%), $\varepsilon$-caprolactone, sodium ascorbate (99\%), and 1-dodecanol were purchased from Alfa Aesar. Doxorubicin hydrochloride, triphosgene, iron(III) acetylacetonate (99\%), benzyl alcohol, $N, N^{\prime}$-carbonyldiimidazole (CDI), L-glutamic acid (99\%), and glutathione (GSH) were purchased from Aladdin Chemical Company. Sodium azide $\mathrm{NaN}_{3}$ (99\%) and cystamine dihydrochloride were purchased from Aldrich. $\varepsilon$-Caprolactone and dimethylformamide (DMF, Shanghai Sinopharm Chemical Reagent Corp., 99.5\%) were distilled from calcium hydride under reduced pressure and stored over molecular sieves. 2Chloroethanol was purchased from Xiya Reagent. Tetrahydrofuran (THF, 99.5\%) and toluene (99.5\%) were refluxed and distilled over sodium benzophenone until a purple color was obtained. Lectin from Triticum vulgaris (wheat) FITC conjugate (LEC-FITC), and lyophilized powder were purchased from Sigma-Aldrich. Dulbecco's Modified Eagle Medium (DMEM), trypsin-ethylenediaminetetraaceticacid (Trypsin-EDTA), and fetal bovine serum (FBS) were purchased from Gibco-BRL (Canada). 3-(4,5-Dimethylthiazol-2-yl)-2,5-diphenyltetrazolium bromide (MTT) was purchased from Invitrogen Corporation (Washington, USA). 4',6-Diamidino-2-phenylindole (DAPI) was purchased from Beyotime Institute of Biotechnology (China). All the other reagents were of analytical grade and used without further purification. The human hepatocellular liver carcinoma (HepG2) cells line was purchased from the Animal Center of the Sun Yat-Sen University (Guangzhou, China). The detailed synthetic method for the SPIO was according to a previous publication..$^{39,40}$

\subsection{Synthesis of PCL-SS- $\mathrm{NH}_{2}$}

2.2.1 Synthesis of PCL via ring-opening polymerization directly initiated from 1-dodecanol. A typical ring-opening polymerization procedure for $\varepsilon$-CL was as follows. A flamed glass ampule with a magnetic stirrer was charged with 1dodecanol (0.028 g, $0.15 \mathrm{mmol}), \varepsilon-\mathrm{CL}(1.03 \mathrm{~g}, 9 \mathrm{mmol})$ and 5.0 $\mathrm{mL}$ of dry toluene. After $1.0 \mathrm{~mL}$ toluene was removed under vacuum to remove traces of water, $\mathrm{Sn}(\mathrm{Oct})_{2}\left(0.1 \mathrm{~mL}, 0.1 \mathrm{~mol} \mathrm{~L}^{-1}\right.$ in toluene) was injected into the reaction mixture and the air was exchanged with nitrogen three times. The glass ampule was immersed in an oil bath at $110{ }^{\circ} \mathrm{C}$ with vigorous stirring to start the polymerization. After $24 \mathrm{~h}$, the reaction mixture was rapidly cooled to room temperature and diluted with THF, and the crude product was precipitated in an excess of petroleum ether. The sediments were collected and dried in vacuum for $48 \mathrm{~h}$ until a constant weight $\left(0.94 \mathrm{~g}, 87.2 \%\right.$ overall yield, $M_{\mathrm{n}}=$ 5729, $\left.M_{\mathrm{w}} / M_{\mathrm{n}}=1.18\right) .{ }^{1} \mathrm{H} \mathrm{NMR}$ analysis in $\mathrm{CDCl}_{3}$ revealed a degree of polymerization (DP) of 37 for the PCL-OH segments. Therefore, this polymer was denoted as $\mathrm{PCL}_{37}-\mathrm{OH}$. ${ }^{1} \mathrm{H}$ NMR (500.10 MHz, $\left.\mathrm{CDCl}_{3}, 298 \mathrm{~K}\right), \delta$, (ppm): 4.1-3.8 $\left(-\mathrm{COOCH}_{2} \mathrm{CH}_{2}-\right), 3.6\left(-\mathrm{CH}_{2} \mathrm{CH}_{2} \mathrm{OH}\right), 2.4-2.2\left(-\mathrm{CH}_{2} \mathrm{CH}_{2} \mathrm{COO}-\right)$, and 1.17-1.12 (- $\left.\mathrm{COOCH}_{2} \mathrm{CH}_{2} \mathrm{CH}_{2} \mathrm{CH}_{2} \mathrm{CH}_{2}-\right)$ of PCL. FTIR $\left(\mathrm{cm}^{-1}\right): 1727,1601,1489,1453$.

2.2.2 Synthesis of the PCL ester of carbonyl imidazole $\left(\mathbf{P C L}_{37}-\mathbf{C I}\right)$. Following the literature, ${ }^{\mathbf{4 1}} 200 \mathrm{~mL}$ anhydrous dichloromethane (DCM) and 1,1'-carbonyldiimidazole (CDI, $2.92 \mathrm{~g}, 18 \mathrm{mmol}$ ) were added into a $500 \mathrm{~mL}$ dry round-bottom flask. Then, $\mathrm{PCL}_{37}-\mathrm{OH}(0.90 \mathrm{~g})$ dissolved in DCM was added dropwise over the course of $30 \mathrm{~min}$. The obtained clear solution was stirred at room temperature for $2 \mathrm{~h}$, washed with water $(3 \times$ $70 \mathrm{~mL}$ ), dried over sodium sulfate, and finally evaporated to obtain a white solid (yield: $13.0 \mathrm{~g}, 87 \%) .8 .16$ (s, 1H, -NCHN-), $7.45(\mathrm{~s}, 1 \mathrm{H},-\mathrm{NCHCHN}-)$ and $7.07(\mathrm{~s}, 1 \mathrm{H},-\mathrm{NCHCHN}-)$ of the imidazole ring, 4.1-3.8 (s, 2H, $\left.-\mathrm{COOCH}_{2} \mathrm{CH}_{2}-\right), 3.6(\mathrm{~s}, 2 \mathrm{H}$, $-\mathrm{CH}_{2} \mathrm{CH}_{2} \mathrm{OH}$ ), 2.4-2.2 (s, 2H, $\left.-\mathrm{CH}_{2} \mathrm{CH}_{2} \mathrm{COO}-\right)$ and 1.17-1.12 (s, $\left.2 \mathrm{H},-\mathrm{COOCH}_{2} \mathrm{CH}_{2} \mathrm{CH}_{2} \mathrm{CH}_{2} \mathrm{CH}_{2}^{-}\right)$of $\mathrm{PCL}_{37}$.

2.2.3 End-group modification of $\mathbf{P C L}_{37}-\mathrm{CI}$. Cystamine dihydrochloride was dissolved in deionized water then neutralized by slowly adding $4 \mathrm{M} \mathrm{NaOH}$ under stirring and extracted with dichloromethane to yield the cystamine. Then, $\mathrm{PCL}_{37}-\mathrm{SS}-\mathrm{NH}_{2}$ was synthesized from $\mathrm{PCL}_{37}-\mathrm{CI}$ with the cystamine, as shown in Scheme 1. Briefly, cystamine (0.40 g, 2.63 $\mathrm{mmol})$ and $\mathrm{PCL}_{37}-\mathrm{CI}(0.94 \mathrm{~g}, 0.164 \mathrm{mmol})$ were dissolved in $50 \mathrm{~mL}$ anhydrous DCM and subsequently stirred at room temperature for $48 \mathrm{~h}$. After evaporation of the dichloromethane, $100 \mathrm{~mL}$ of $1.0 \mathrm{M} \mathrm{NaH}_{2} \mathrm{PO}_{4}$ (pH 4.0) was added. The aqueous solution was extracted with DCM $(50 \mathrm{~mL}, 3$ 
times), combined with the organic phase and then dried over sodium sulfate. After evaporating the DCM, a white solid was obtained (yield: $0.83 \mathrm{~g}, 88.3 \%) .{ }^{1} \mathrm{H} \mathrm{NMR}\left(500.10 \mathrm{MHz}, \mathrm{CDCl}_{3}\right.$, $298 \mathrm{~K}), \delta,(\mathrm{ppm}): 8.19$ (s, 1H, NCHN), 7.45 (s, 1H, NCHCHN), $7.10(\mathrm{~s}, 1 \mathrm{H}, \mathrm{NCHCHN}), 5.0\left(\mathrm{~s}, 2 \mathrm{H}, \mathrm{OCH}_{2} \mathrm{C}\right)$, and $2.63(\mathrm{~s}, 1 \mathrm{H}$, $\mathrm{CCH})$.

\subsection{Synthesis of $\gamma$-(2-azidoethyl)-L-glutamic acid-based $N$ - carboxyanhydride (AELG-NCA)}

To a solution of L-glutamic acid (15 g, $0.1 \mathrm{~mol})$ suspended in anhydrous ethyl ether $(100 \mathrm{~mL})$ and 2 -azide ethanol $(20 \mathrm{~mL})$ at $0{ }^{\circ} \mathrm{C}, 8 \mathrm{~mL}$ of sulfuric acid was added dropwise over the course of $c a .20 \mathrm{~min}$. After removing the ethyl ether under reduced pressure, the reaction mixture was stirred at room temperature for $24 \mathrm{~h}$. The solution was neutralized with pyridine. After storing in a refrigerator overnight, there was a white precipitate formed. The crude product was obtained after filtration. The crude product was washed with ethanol to afford $\gamma$-(2-azidoethyl)-L-glutamate as a white solid (5.0 g, 23.7\%). ${ }^{1} \mathrm{H}$ NMR $\left(\mathrm{D}_{2} \mathrm{O}, \delta,(\mathrm{ppm})\right): 3.8\left(\mathrm{t}, 1 \mathrm{H}, \mathrm{NH}_{2} \mathrm{CH}\right), 2.1\left(\mathrm{~m}, 2 \mathrm{H},-\mathrm{CHCH}_{2} \mathrm{CH}_{2}-\right)$, $2.6\left(\mathrm{t}, 2 \mathrm{H},-\mathrm{COCH}_{2} \mathrm{CH}_{2}-\right), 4.5\left(\mathrm{t}, 2 \mathrm{H},-\mathrm{OCH}_{2} \mathrm{CH}_{2} \mathrm{~N}_{3}\right), 3.7(\mathrm{t}, 2 \mathrm{H}$, $\left.\mathrm{ClCH}_{2} \mathrm{CH}_{2}^{-}\right)$.

$\gamma$-(2-Azidoethyl)-L-glutamate $(4.2 \mathrm{~g}, 20 \mathrm{mmol})$ and triphosgene $(2.0 \mathrm{~g}, 6.74 \mathrm{mmol})$ were suspended in $60 \mathrm{~mL}$ of dry THF bubbling with a slow steady nitrogen flux in a flame-dry three-neck flask. The mixture was stirred in a $50{ }^{\circ} \mathrm{C}$ oil bath until the cloudy solution turned clear. The mixture was concentrated by reduced pressure distillation, and a yellowish oil was obtained, which was dissolved in $100 \mathrm{~mL}$ ethyl acetate, followed by washing with $50 \mathrm{~mL} 0.5 \% \mathrm{NaHCO}_{3}$ ice-cold aqueous solution three times. The organic phase was then dried over anhydrous $\mathrm{MgSO}_{4}$ and evaporated to give AELG-NCA as a viscous oil (3.4 $\mathrm{g}, 70 \%)$.

\subsection{Synthesis of PCL-SS-PAELG}

Inside a glovebox, the initiator $\mathrm{PCL}_{37}-\mathrm{SS}-\mathrm{NH}_{2}(0.40 \mathrm{~g}, 0.068$ mmol) was dissolved in $15 \mathrm{~mL}$ DMF in a Schlenk tube. A solution of AELG-NCA $(0.33 \mathrm{~g}, 1.36 \mathrm{mmol})$ in $5 \mathrm{~mL}$ dry DMF was added after $\mathrm{PCL}_{37}-\mathrm{SS}-\mathrm{NH}_{2}$ was dissolved completely. The reaction mixture was stirred at room temperature for $72 \mathrm{~h}$, and after that the reaction mixture was dialyzed against deionized water to remove the organic solution. A white precipitate appeared, which after filtration and drying under vacuum at $40{ }^{\circ} \mathrm{C}$ for $12 \mathrm{~h}$ afforded the final product as a white solid $(0.62 \mathrm{~g}$, $92 \%) .{ }^{1} \mathrm{H}$ NMR analysis in $\mathrm{CDCl}_{3}$ revealed the degree of polymerization (DP) of 10 for the polypeptide block. Therefore, this polymer was denoted as $\mathrm{PCL}_{37}-\mathrm{SS}_{-} \mathrm{PAELG}_{10} \cdot{ }^{1} \mathrm{H}$ NMR $((500$ $\left.\left.\mathrm{MHz}, \mathrm{CDCl}_{3} / \mathrm{CF}_{3} \mathrm{CO}_{2} \mathrm{D}, \mathrm{v} / \mathrm{v}=85 / 15,298 \mathrm{~K}\right), \delta, \mathrm{ppm}\right): 0.88(\mathrm{t}, 3 \mathrm{H}$, $\left.\mathrm{CH}_{3} \mathrm{CH}_{2}-\right), 1.26\left(\mathrm{~m}, 2 \mathrm{H}, \mathrm{CH}_{3} \mathrm{CH}_{2}^{-}\right), 1.34-1.43\left(\mathrm{~m}, 2 \mathrm{H},-\mathrm{CH}_{2^{-}}\right.$ $\left.\mathrm{CH}_{2} \mathrm{CH}_{2} \mathrm{O}-\right)$, 1.59-1.76 (m, 4H, $\left.-\mathrm{CH}_{2} \mathrm{CH}_{2} \mathrm{CH}_{2} \mathrm{CH}_{2}-\right)$, 1.91-2.25 (m, $\left.2 \mathrm{H},-\mathrm{CHCH}_{2} \mathrm{CH}_{2}-\right)$, 2.33-2.42 (m, 2H, - $\left.\mathrm{COOCH}_{2} \mathrm{CH}_{2}-\right)$, 2.47$2.60\left(\mathrm{~s}, 2 \mathrm{H},-\mathrm{CH}_{2} \mathrm{CH}_{2} \mathrm{COO}-\right), 3.47-3.59\left(\mathrm{~s}, 2 \mathrm{H},-\mathrm{CH}_{2} \mathrm{CH}_{2} \mathrm{~N}_{3}\right.$ ), 4.05-4.14 (t, 2H, $\left.-\mathrm{CH}_{2} \mathrm{CH}_{2} \mathrm{OCO}-\right)$, 4.20-4.36 (s, 2H, $-\mathrm{OCH}_{2} \mathrm{CH}_{2}-$ $\mathrm{N}_{3}$ ), 4.50-4.67 (s, 2H, -COCHNH-).

\subsection{Synthesis of polycaprolactone-block-}

poly(glutamategalactose) ( $\left.\mathrm{PCL}_{37}-\mathrm{SS}-\mathrm{PGluGal}_{10}\right)$ by click conjugation

The process for the click conjugation of propargylgalactose to the PCL $_{37}-$ SS-PAELG ${ }_{10}$ block copolymers started with $0.1 \mathrm{~g}$ of PCL $_{37}$-SS-PAELG 10 block copolymers containing about $0.20 \mathrm{mmol}$ azide pendants and $0.126 \mathrm{~g}$ of propargylgalactose $(0.54 \mathrm{mmol})$ being first dissolved in $10 \mathrm{~mL}$ of DMSO with argon bubbling. After the block copolymers and propargylgalactose dissolved completely, $15 \mathrm{mg}$ of $\mathrm{CuSO}_{4} \cdot 5 \mathrm{H}_{2} \mathrm{O}$ was introduced into the flask and the mixture was further bubbled with argon for about $10 \mathrm{~min}$ until $30 \mathrm{mg}$ of sodium ascorbate (NaAsc) was added. Then the flask was sealed under argon and immersed in an oil bath at $40{ }^{\circ} \mathrm{C}$ for 3 days. The reaction medium was transferred to a $3.5 \mathrm{kDa}$ molecular weight cut-off (MWCO) dialysis membrane and dialyzed first against ethylenediaminetetraacetic acid (EDTA) for 3 days, then against pure water for 3 days in order to remove the copper and ascorbate salts as well as excess propargylgalactose. The final product was obtained as a white solid by lyophilization. Yield: $0.126 \mathrm{~g}, 85 \%$. ${ }^{1} \mathrm{H}$ NMR (DMSO- $d_{6}$ ): 0.88 (t, 3H, $\left.\mathrm{CH}_{3} \mathrm{CH}_{2}-\right), 1.26\left(\mathrm{~m}, 20 \mathrm{H}, \mathrm{CH}_{3} \mathrm{CH}_{2}-\right)$, 1.34-1.43 (m, $2 \mathrm{H},-\mathrm{CH}_{2} \mathrm{CH}_{2} \mathrm{CH}_{2} \mathrm{O}-$ ), 1.59-1.76 (m, 4H, $-\mathrm{CH}_{2} \mathrm{CH}_{2} \mathrm{CH}_{2} \mathrm{CH}_{2}-$ ), 1.91-2.25 (m, 2H, $\left.-\mathrm{CHCH}_{2} \mathrm{CH}_{2}-\right), 2.33-2.42(\mathrm{~m}, 2 \mathrm{H}$, $-\mathrm{COOCH}_{2} \mathrm{CH}_{2}-$ ), 2.47-2.60 (s, 2H, $-\mathrm{CH}_{2} \mathrm{CH}_{2} \mathrm{COO}-$ ), 3.47-3.59 $\left(\mathrm{s}, 2 \mathrm{H},-\mathrm{CH}_{2} \mathrm{CH}_{2} \mathrm{~N}_{3}\right), 4.05-4.14\left(\mathrm{t}, 2 \mathrm{H},-\mathrm{CH}_{2} \mathrm{CH}_{2} \mathrm{OCO}-\right), 4.20-$ $4.36\left(\mathrm{~s}, 2 \mathrm{H},-\mathrm{OCH}_{2} \mathrm{CH}_{2} \mathrm{~N}_{3}\right), 4.50-4.67$ (s, 2H, -COCHNH-), 5.13.4 t (Gla H-2, H-3, H-4, H-5, H-6), 8.07 ppm (s, $\left.1 \mathrm{H},-\mathrm{CONH}_{-}\right)$ and $8.15 \mathrm{ppm}(\mathrm{s}, 1 \mathrm{H}, \mathrm{C}=C H \mathrm{~N}-)$.

\subsection{Synthesis of polycaprolactone-block- poly(glutamatelactose) ( PCL $_{37}-$ SS-PGluLac $\left.{ }_{10}\right)$ by click conjugation}

Click conjugation between propargyllactose and the $\mathrm{PCL}_{37}$ SS-PAELG ${ }_{10}$ block copolymers started with $0.1 \mathrm{~g}$ of PCL-SSPAELG block copolymers containing about $0.20 \mathrm{mmol}$ azide pendants and $0.22 \mathrm{~g}$ of propargyllactose $(0.54 \mathrm{mmol})$ being first dissolved in $10 \mathrm{~mL}$ of DMSO with argon bubbling. After the block copolymers and propargyllactose dissolved completely, $15 \mathrm{mg}$ of $\mathrm{CuSO}_{4} \cdot 5 \mathrm{H}_{2} \mathrm{O}$ was introduced into the flask and the mixture was further bubbled with argon for about $10 \mathrm{~min}$ until $30 \mathrm{mg}$ of sodium ascorbate (NaAsc) was added. Then the flask was sealed under argon and immersed in an oil bath at $40{ }^{\circ} \mathrm{C}$ for 3 days. The reaction medium was transferred to a $3.5 \mathrm{kDa}$ molecular weight cut-off (MWCO) dialysis membrane and dialyzed first against ethylenediaminetetraacetic acid (EDTA) for 3 days, then against pure water for 3 days in order to remove the copper and ascorbate salts as well as excess propargyllactose. The final product was obtained as a white solid by lyophilization. Yield: $0.146 \mathrm{~g} 82 \%$. ${ }^{1} \mathrm{H}$ NMR (DMSO- $d_{6}$ ): $0.88\left(\mathrm{t}, 3 \mathrm{H}, \mathrm{CH}_{3} \mathrm{CH}_{2}-\right.$ ), 1.26 (m, 20H, $\left.\mathrm{CH}_{3} \mathrm{CH}_{2}-\right)$, 1.34-1.43 (m, 2H, $\left.-\mathrm{CH}_{2} \mathrm{CH}_{2} \mathrm{CH}_{2} \mathrm{O}-\right)$, 1.59$1.76\left(\mathrm{~m}, 4 \mathrm{H},-\mathrm{CH}_{2} \mathrm{CH}_{2} \mathrm{CH}_{2} \mathrm{CH}_{2}-\right)$, 1.91-2.25 (m, 2H, $-\mathrm{CHCH}_{2}-$ $\left.\mathrm{CH}_{2}{ }^{-}\right), 2.33-2.42\left(\mathrm{~m}, 2 \mathrm{H},-\mathrm{COOCH}_{2} \mathrm{CH}_{2}-\right), 2.47-2.60(\mathrm{~s}, 2 \mathrm{H}$, $-\mathrm{CH}_{2} \mathrm{CH}_{2} \mathrm{COO}-$ ), 3.47-3.59 (s, 2H, $-\mathrm{CH}_{2} \mathrm{CH}_{2} \mathrm{~N}_{3}$ ), 4.05-4.14 (t, $\left.2 \mathrm{H},-\mathrm{CH}_{2} \mathrm{CH}_{2} \mathrm{OCO}-\right)$, 4.20-4.36 (s, 2H, $\left.-\mathrm{OCH}_{2} \mathrm{CH}_{2} \mathrm{~N}_{3}\right), 4.50-$ 
4.67 (s, 2H, -COCHNH-), 5.1-3.4 t (Lac H-2, H-3, H-4, H-5, H-6, $\mathrm{H}-7, \mathrm{H}-8, \mathrm{H}-9, \mathrm{H}-10, \mathrm{H}-11, \mathrm{H}-12), 8.07$ ppm (s, 1H, -CONH-) and $8.15 \mathrm{ppm}(\mathrm{s}, 1 \mathrm{H}, \mathrm{C}=C H \mathrm{~N}-)$.

\subsection{Characterization}

A Perkin-Elmer Paragon 1000 spectrometer was used to record the FTIR spectra of all the samples in transmission mode. Samples were ground with $\mathrm{KBr}$ and then compressed into pellets. The spectra were taken at the frequencies ranging from 500 to $4000 \mathrm{~cm}^{-1}$. ${ }^{1} \mathrm{H}$ NMR spectra of the compounds were characterized on a Bruker 500 NMR spectrometer using deuterated chloroform $\left(\mathrm{CDCl}_{3}-d\right)$ or deuterated dimethyl sulfoxide (DMSO- $d_{6}$ ) as the solvent and tetramethylsilane (TMS) as the internal standard. The size and size distribution of the micellar aggregates were determined by dynamic light scattering (DLS) using the BI-200SM Goniometer particle size analyzer (Brookhaven Instruments Corporation, USA). Each analysis lasted for $300 \mathrm{~s}$ and the data were collected on an autocorrelator at $25{ }^{\circ} \mathrm{C}$ with a detection angle of scattered light at $90^{\circ}$. For each sample, the data from three measurements were averaged to obtain the mean \pm standard deviation (SD). The morphology images of the micelles were obtained on a JEOL JEM-2100F transmission electron microscope (JEM-2100F, JEOL, Tokyo, Japan) at an accelerating voltage of $200 \mathrm{keV}$. In brief, $10 \mu \mathrm{L}$ of $0.5 \mathrm{mg} \mathrm{mL}{ }^{-1}$ micelle suspension on the copper grid was stained with a small drop of $1 \mathrm{wt} \%$ phosphotungstic acid solution ( $2 \mathrm{wt} \%$ in water). The grid was finally dried overnight at room temperature before TEM observation.

\subsection{Self-assembly behavior of the amphiphilic PCL-SS-GPPs}

To study the self-assembly behavior, the PCL-SS-GPPs in deionized water were prepared by the dialysis method as follows: $10 \mathrm{mg}$ PCL-SS-GPPs, including PCL $_{37}-\mathrm{SS}-\mathrm{PGluGal}_{10}$ and PCL $_{37}-$ SS-PGluLac 10 , were first dissolved in $2 \mathrm{~mL}$ warm DMSO. Then, $4.0 \mathrm{~mL}$ of deionized water was added dropwise into the DMSO slowly via a syringe pump under stirring at room temperature. The organic solvent was removed by dialysis against PB for $24 \mathrm{~h}$ at $25{ }^{\circ} \mathrm{C}$ using a cellulose membrane bag (molecular weight cut-off, MWCO 3500-4000).

The critical micelle concentration (CMC) of the PCL-SSGPPs was determined using pyrene as a fluorescence probe. The concentration of the PCL-SS-GPPs varied from 1.0 to $4.88 \times$ $10^{-4} \mathrm{mg} \mathrm{mL}^{-1}$ and the final concentration of pyrene was fixed at $6.0 \times 10^{-7} \mathrm{~mol} \mathrm{~L}^{-1}$. Before the measurement, the mixed solution of pyrene and PCL-SS-GPPs were kept on a shaker at $37{ }^{\circ} \mathrm{C}$ for $24 \mathrm{~h}$ to reach solubilization equilibrium in the dark. The fluorescence spectra were recorded using a fluorescence spectrometer (RF-5301 PC Shimadzu), where the excitation spectra of the PCL-SS-GPPs/pyrene solutions were scanned from 300 to $350 \mathrm{~nm}$ at room temperature, with an emission wavelength of $373 \mathrm{~nm}$ and a bandwidth of $5 \mathrm{~nm}$. The intensity ratios of $I_{337}$ to $I_{335}$ were plotted as a function of logarithm of the PCL-SS-GPPS concentrations. The CMC value was estimated from the intersection of the tangent to the curve at the inflection with the horizontal tangent through the points at low concentrations.

\subsection{Preparation of DOX and SPIO co-loading micelles}

The hydrophobic DOX and SPIO could be loaded into the hydrophobic inner core of the micelles through a dialysis method. In brief, $10 \mathrm{mg}$ PCL-SS-GPPs, $2 \mathrm{mg} \mathrm{DOX} \cdot \mathrm{HCl}$, an equimolar amount of triethylamine (TEA), and $1.5 \mathrm{mg}$ SPIO were dissolved in $2 \mathrm{~mL}$ DMSO. Next, $5 \mathrm{~mL}$ of deionized water was slowly added into the above mixed solution under moderate stirring. The mixed solution was dialyzed against deionized water with a molecular weight cut-off (MWCO) of $3500 \mathrm{Da}$ at room temperature, with the dialysis water was changed every $8 \mathrm{~h}$, to allow the formation of DOX/SPIO-loaded PCL-SS-GPPs micelles and to remove the DMSO and unencapsulated DOX and SPIO.

\subsection{Determination of the DOX- and SPIO-loading contents}

The DOX loading in the micelles was determined by fluorescence spectrophotometry. The DOX/SPIO-loaded PCL-SS-GPPS micelles were first broken in a mixed DMSO/PBS solvent (v/v, 70/ 30 ), then the sample was filtered to remove the insoluble SPIO and subjected to UV analysis (UV-3150, Shimadzu, Japan) at a wavelength of $480 \mathrm{~nm}$. The loading amount of DOX was determined from the calibration curve of DOX. The drugloading content (DLC) was calculated according to the following equation:

$$
\operatorname{DLC}(\%)=w_{1} / w_{2} \times 100
$$

where $w_{1}$ is the weight of loaded drug and $w_{2}$ is the weight of the drug-loaded micelles.

The loading amount of SPIO NPs inside the PCL-SS-GPPs micelles was determined using an atomic absorption spectrophotometer (AAS). In brief, the DOX/SPIO-loaded PCL-SS-GPPS micelles were added to $1 \mathrm{M} \mathrm{HCl}$ solution to allow the disaggregation of micelles and the complete dissolution of the SPIO NPs. The Fe concentration was determined at the specific Fe absorption wavelength $(248.3 \mathrm{~nm})$ based on a previously established calibration curve. The SPIO-loading content was calculated as the ratio of SPIO to the total weight of the SPIOloaded micelles.

$$
\operatorname{SLC}(\%)=w_{3} / w_{4} \times 100
$$

where $w_{3}$ is the weight of loaded SPIO and $w_{4}$ is the weight of SPIO-loaded micelles.

\subsection{In vitro release of DOX}

The in vitro release behavior of loaded DOX from the PCL-SSGPPs micelles were studied at $37{ }^{\circ} \mathrm{C}$ in two different release media, where the DOX/SPIO-loaded PCL-SS-GPPs micelles were suspended in $3 \mathrm{~mL}$ of PBS with various GSH concentrations (0 and $10 \mathrm{mM}$ ), and then the micelle solution was immediately transferred into a dialysis bag (MWCO $3500 \mathrm{Da}$ ). The release experiment was initiated by placing the end-sealed dialysis bag in $27 \mathrm{~mL}$ of PBS containing 0 or $10 \mathrm{mM}$ GSH with gentle shaking in a $37{ }^{\circ} \mathrm{C}$ water bath at $100 \mathrm{rpm}$. At predetermined time intervals, $3 \mathrm{~mL}$ release medium outside the dialysis bag was removed and subsequently replenished with $3 \mathrm{~mL}$ fresh 
buffered solution. The amount of released DOX was determined using a UV-vis spectrometer (UV-3150, Shimadzu, Japan) at $480 \mathrm{~nm}$.

$$
E_{\mathrm{r}}(\%)=\frac{V_{0} \sum_{1}^{n-1} C_{i}+V_{0} C_{n}}{m_{\mathrm{DOX}}} \times 100 \%
$$

where $V_{0}$ is the whole volume of the release media $\left(V_{0}=30 \mathrm{~mL}\right)$, $V_{\mathrm{e}}$ is the volume of the replace media $\left(V_{\mathrm{e}}=3 \mathrm{~mL}\right), m_{\text {Dox }}$ represents the amount of doxorubicin in the micelles, and $C_{i}$ represents the concentration of DOX in the $i$ th sample.

\subsection{In vitro lectin recognition bioactivity}

$1 \mathrm{~mL}\left(1 \mathrm{mg} \quad \mathrm{mL}^{-1}\right) \quad \mathrm{PCL}_{37}-\mathrm{SS}-\mathrm{PGluGal}_{10}$ and $\mathrm{PCL}_{37}-\mathrm{SS}-$ PGluLac $_{10}$ micelles solutions were added into the 6-well plate, then after the water was evaporated off the PCL-SS-GPPs films were obtained. These films were treated with methanol for $1 \mathrm{~h}$ and then dried for $24 \mathrm{~h}$. The insoluble $\mathrm{PCL}_{37}-\mathrm{SS}-\mathrm{PGluGal}_{10}$ and PCL $_{37}$-SS-PGluLac ${ }_{10}$ films were incubated with LEC-FITC solution $\left(0.5 \mathrm{mg} \mathrm{mL}^{-1}\right)$ at room temperature for $30 \mathrm{~min}$. The films were washed with $100 \mathrm{mM}$ phosphate buffer three times. The bioavailability of the galactose moieties on the PCL-SS-GPPS films with LEC-FITC were observed by a Carl Zeiss inverted fluorescence microscope.

\subsection{Cell viability assays}

Using a MTT assay, the in vitro relative cytotoxicities of the empty PCL-SS-GPPs micelles against human hepatocellular liver carcinoma (HepG2) cells were evaluated. Five multiple holes were set for every sample. The HepG2 cells were seeded in a 96-well plate at a density of $1 \times 10^{4}$ cells per well in $100 \mu \mathrm{L}$ of DMEM and incubated under a $5 \% \mathrm{CO}_{2}$ atmosphere at $37^{\circ} \mathrm{C}$ for $24 \mathrm{~h}$. After removing the culture medium, the PCL-SS-GPPs micelles solution was added to the wells at a specific concentration $\left(0-500 \mu \mathrm{g} \mathrm{mL}{ }^{-1}\right)$. After co-incubation with the cells for $48 \mathrm{~h}, 20 \mu \mathrm{L}$ of MTT solution in PBS ( $5 \mathrm{mg} \mathrm{mL}^{-1}$ ) was added to each well and the plate was incubated for another $4 \mathrm{~h}$ at $37^{\circ} \mathrm{C}$. After that, the medium containing MTT was removed, and 150 $\mu \mathrm{L}$ of DMSO was added to each well to dissolve the MTT formazan crystals. Finally, the plates were shaken for $10 \mathrm{~min}$, and the absorbance of formazan product was measured at $490 \mathrm{~nm}$ by a microplate reader.

$$
\text { Cell viability }(\%)=\left[A_{490}(\text { sample }) / A_{490}(\text { control })\right] \times 100
$$

where $A_{490}$ (sample) and $A_{490}$ (control) represented the absorbances of the sample and control wells, respectively.

The in vitro antitumor activity of DOX/SPIO-loaded hepatomatargeting PCL-SS-GPPs micelles against the asialoglycoprotein receptor (ASGP-R) overexpressing HepG2 cells was evaluated by MTT assay. Briefly, the HepG2 cells were respectively cultured onto 96-well plates at a density of $1 \times 10^{4}$ cells per well and incubated in a humidified atmosphere of $5 \% \mathrm{CO}_{2}$ at $37{ }^{\circ} \mathrm{C}$ for $24 \mathrm{~h}$. After that, the growth medium was replaced by $100 \mu \mathrm{L}$ complete DMEM containing different DOX concentrations (0-10 $\mu \mathrm{g} \mathrm{mL}{ }^{-1} \mathrm{DOX}$ ) and further incubated for $24 \mathrm{~h}$. After co-incubation with the cells for $24 \mathrm{~h}, 20 \mu \mathrm{L}$ of MTT solution in PBS $\left(5 \mathrm{mg} \mathrm{mL}{ }^{-1}\right)$ was added to each well and the plate was incubated for another $4 \mathrm{~h}$ at $37{ }^{\circ} \mathrm{C}$. After that, the medium containing MTT was removed, and $150 \mu \mathrm{L}$ of DMSO was added to each well to dissolve the MTT formazan crystals. Finally, the plates were shaken for $10 \mathrm{~min}$, and the absorbance of the formazan product was measured at $490 \mathrm{~nm}$ by a microplate reader. The relative cell viability (\%) was calculated based on the above method. Herein, the data are presented as the average $\pm \operatorname{SD}(n=3)$.

\subsection{Cellular uptake studies}

The cellular uptake and distribution of micelles were performed using flow cytometry (Guava easyCyte 5HT-2L, Merck Millipore, Germany) and inverted fluorescence microscopy (Axio Observer.Z1, Carl Zeiss, Germany). For flow cytometry, the HepG2 cells were seeded in 6 -well plates at a density of $1 \times 10^{6}$ cells per well in $2 \mathrm{~mL}$ of complete DMEM and cultured at $37^{\circ} \mathrm{C}$ in the $5 \% \mathrm{CO}_{2}$ atmosphere overnight. Cells were then washed with PBS and incubated with the free DOX and DOX/SPIO-loaded PCL-SSGPPs micelles (DOX concentration: $10 \mathrm{mg} \mathrm{mL}^{-1}$ ) at $37^{\circ} \mathrm{C}$ for an additional $4 \mathrm{~h}$. Cells without pretreatment were used for comparison. After the culture medium was removed, the cells were washed with PBS three times and treated with trypsin. Then, $2 \mathrm{~mL}$ of PBS was added to each culture well, and the cells were collected after centrifuging the solutions for $5 \mathrm{~min}$ at $3000 \mathrm{rpm}$. After removal of the supernatants, the cells were resuspended in $0.3 \mathrm{~mL}$ of PBS. A minimum of $2 \times 10^{4}$ cells were analyzed from each sample.

For the inverted fluorescence microscope studies, HepG2 cells were seeded in a 6 -well plate $\left(1 \times 10^{6}\right.$ cell per well $)$ in $2 \mathrm{~mL}$ of DMEM and cultured at $37^{\circ} \mathrm{C}$ in the $5 \% \mathrm{CO}_{2}$ atmosphere for $24 \mathrm{~h}$. In order to observe the cells internalization, the culture medium was replaced with $2 \mathrm{~mL}$ of DMEM containing the free DOX and DOX/SPIO-loaded micelles (DOX concentration: $10 \mu \mathrm{g}$ $\mathrm{mL}^{-1}$ ). After $4 \mathrm{~h}$, the culture medium was removed and the cells were washed with PBS; the cells were then fixed with $4 \%$ formaldehyde for $30 \mathrm{~min}$ at room temperature, and the slides were rinsed with PBS three times. The cell nuclei were dyed with 4,6-diamidino-2-phenylindole (DAPI) for $30 \mathrm{~min}$ and washed with PBS three times. Finally, the samples were observed by the inverted fluorescence microscope, and the photos were obtained with a $20 \times$ objective. The samples were excited using a Mercury HBO Power instrument. The excitation wavelengths of DOX and DAPI were $546 \pm 12 \mathrm{~nm}$ and $365 \mathrm{~nm}$, respectively.

\subsection{Relaxivity measurements}

The $T_{2}$ relaxivity of the DOX/SPIO-loaded micelles was measured by using a 3.0T MRI scanner (Verio, Siemens, Erlangen, Germany) at room temperature. The $T_{2}$ mapping sequence $\left(T_{\mathrm{R}}: 1000 \mathrm{~ms}, T_{\mathrm{E}}: 13.8 / 27.6 / 41.4 / 55.2 / 69.0 \mathrm{~ms}\right.$, flip angle: $180^{\circ}$, slice thickness: $3.0 \mathrm{~mm}$, matrix $444 \times 448$ ) was used to measure the transverse relaxation time. The relaxation times were obtained by fitting the multi-echo data to a monoexponential decay curve using linearized least-squares optimization. The relaxivity values were calculated via linear least-squares fitting of $1 /$ relaxation time $\left(\mathrm{s}^{-1}\right)$ versus the iron concentration (mM Fe). 
(A) Synthesis of PCL-SS-NH

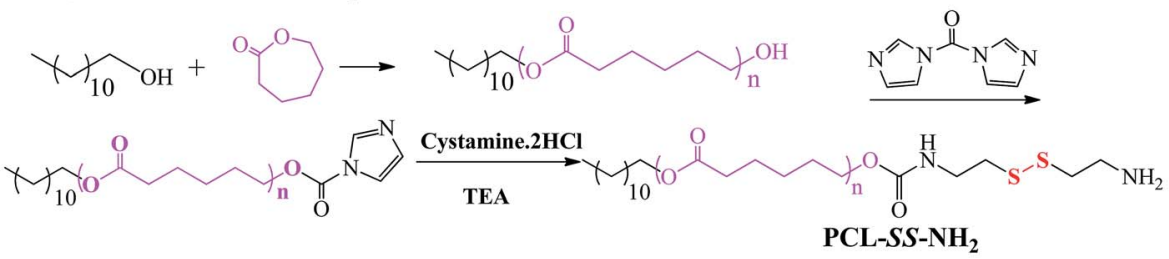

(B) preparation of AELG-NAC

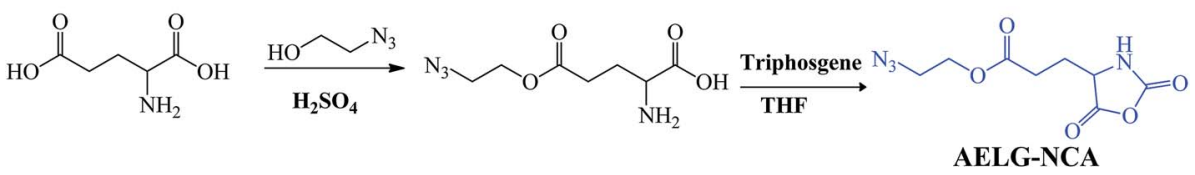

(C) Preparation of the PCL-SS-PAELG

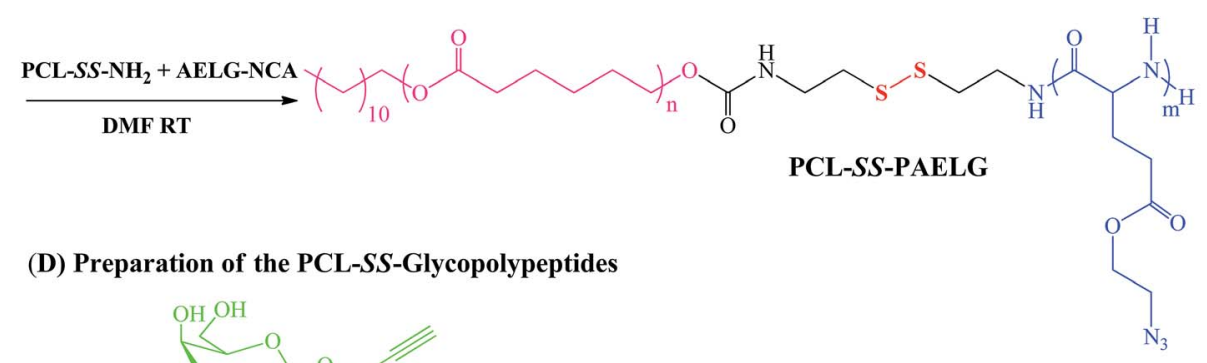

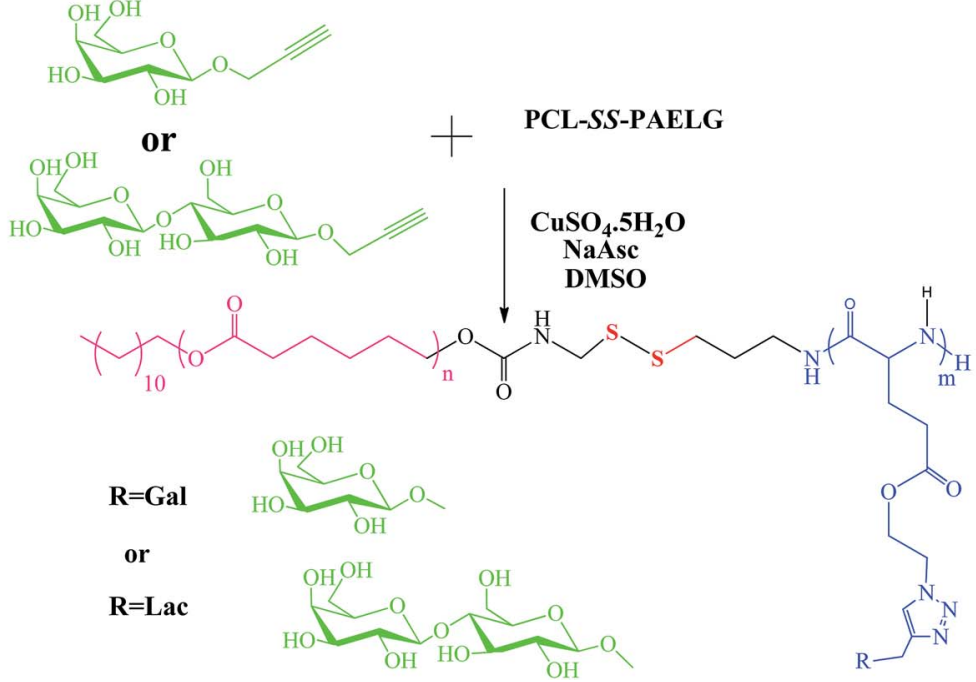

Scheme 2 Synthesis of amphiphilic PCL-SS-GPPs diblock copolymers.

\section{Results and discussion}

\subsection{Preparation and characterization of disulfide-bonds- linked PCL-SS-GPPs copolymers}

The diblock copolymers were synthesized by the combination of sequential ROP of the $\varepsilon$-CL and AELG-NCA monomers follow by the click conjugation of the saccharide units on the polypeptide blocks (see Scheme 2). Generally, PCL prepared by $\varepsilon$-CL ROP have a well-defined chain length, low polydispersity index, and a hydroxy end-group. The hydroxyl end-group can be modified into an amine group and thus acts as an initiator for NCA ROP. The precursors with the terminal amine group and disulfide bonds were prepared from the PCL-CI reacting with cystamine.
The obtained PCL with the terminal amine were then reacted with AELG-NCA in DMF to obtain PCL-SS-PAELG. Fig. 1a and b display the ${ }^{1} \mathrm{H}$ NMR spectra of PCL terminated with carbonylimidazole and amine groups, respectively. In this paper, the PCL- $\mathrm{NH}_{2}$ with a polymerization degree of 37 was used as a macroinitiator to polymerize AELG-NCA. As shown in Fig. 1c, the composition of the final block of PCL-SS-PAELG was estimated based on the integrals at 4.1 and 3.5 ppm from the corresponding spectrum for the PCL and PAELG residues, respectively. Alkyne and azide click conjugation was widely used as an effective synthetic method to form highly functionalized polypeptides. In our experiment, the PCL-SS-glycopolypeptides were obtained through a click conjugation between 
(a)

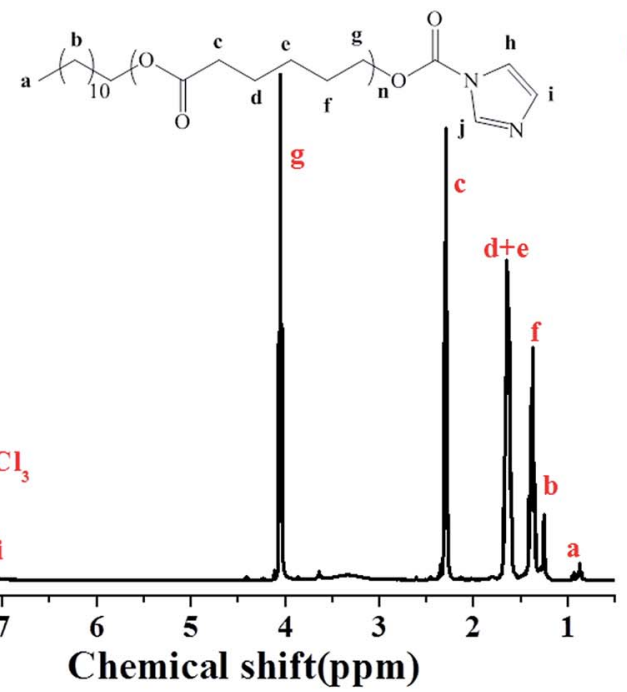

(c)

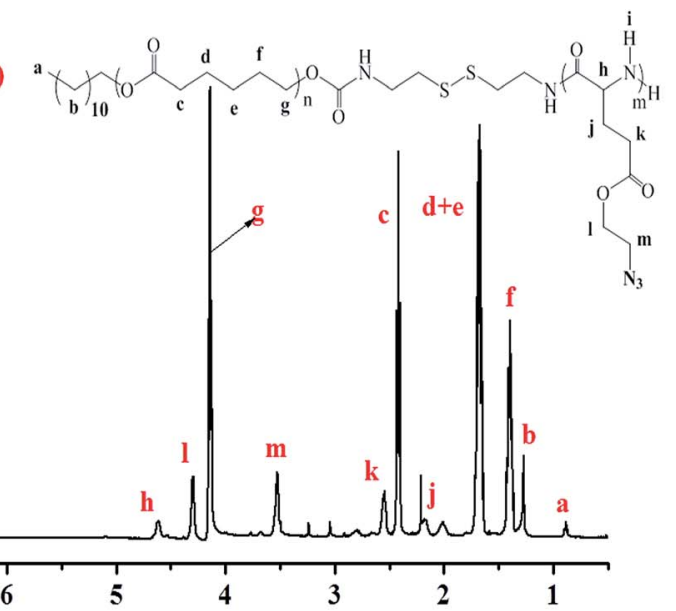

Chemical shift(ppm) (b)

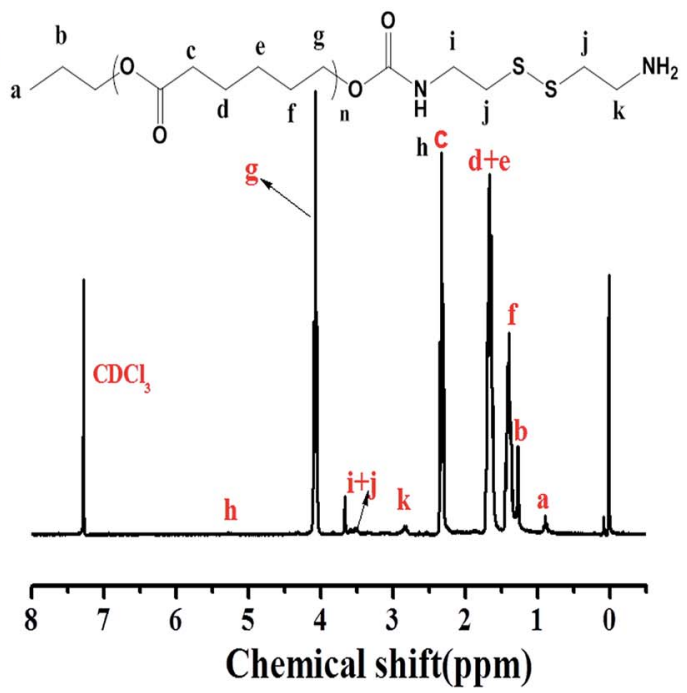

(d)

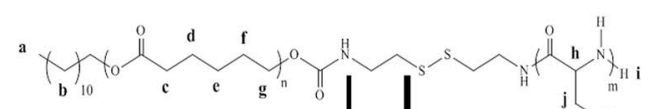

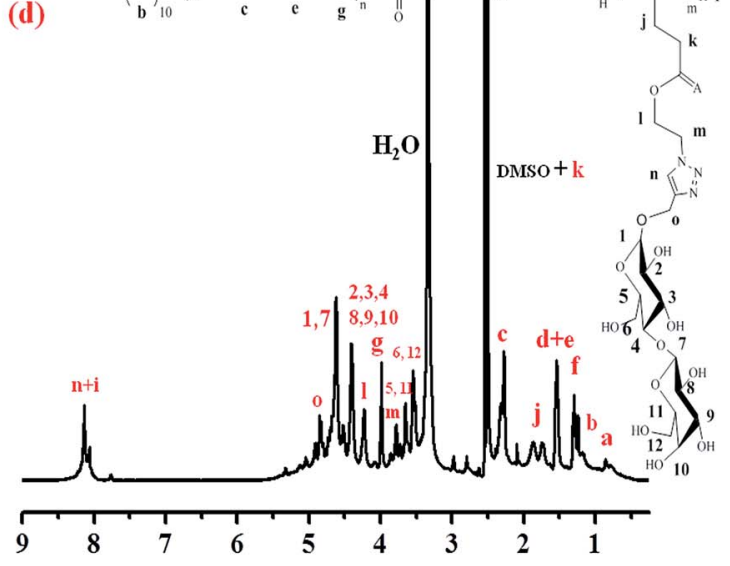

Chemical shift(ppm)

Fig. $1{ }^{1} \mathrm{H} N M R$ spectra of $\mathrm{PCL}-\mathrm{Cl}$ in $\mathrm{CDCl}_{3}$ (a), PCL-SS-NH $\mathrm{NH}_{2}$ in $\mathrm{CDCl}_{3}$ (b), $\mathrm{PCL}_{37}-\mathrm{SS}-\mathrm{PAELG} 10$ in $\mathrm{CDCl}_{3}$ containing $15 \%$ TFA (c), and PCL $37-\mathrm{SS}-$ PGluLac 10 in DMSO-d $(d)$.

propargylgalactose/propargyllactose with PCL-SS-PAELG in DMSO at $45{ }^{\circ} \mathrm{C}$ using $\mathrm{CuSO}_{4} /$ sodium ascorbate as a catalyst. ${ }^{1} \mathrm{H}$ NMR spectra shown in Fig. 1d revealed new signals from the sugar. In addition, the characteristic signal at $8.0 \mathrm{ppm}$ is attributed to the proton from the triazole ring. According to the ${ }^{1} \mathrm{H}$ NMR spectrum of $\mathrm{PCL}_{37}-\mathrm{SS}-\mathrm{PGluLac}_{10}$, the resonances for the triazole protons (h, Fig. 1d) are integrated in an approximate $1: 6$ ratio relative to the polypeptide side chains (c-f of Fig. 1b), suggesting a nearly quantitative grafting efficiency. The high grafting efficiency observed from these polymers is consistent with the existing reports on the synthesis of glycolpolypeptides.

Fig. 2 shows the FTIR spectra of PCL-SS-GPPs and its precursors. As shown in the FTIR spectra, the characteristic absorption bands of PCL-SS-NH $\mathrm{NH}_{2}$ appear at $2934 \mathrm{~cm}^{-1}$ and $2841 \mathrm{~cm}^{-1}(\nu \mathrm{C}-\mathrm{H})$, and $1739 \mathrm{~cm}^{-1}(\nu \mathrm{C}=\mathrm{O})$. The absorption bands attributed to $\mathrm{PCL}_{37}-\mathrm{SS}-\mathrm{PAELG}_{10}$ appear at $3290 \mathrm{~cm}^{-1}(\nu$
$\mathrm{N}-\mathrm{H}), 2934 \mathrm{~cm}^{-1}$, and $2841 \mathrm{~cm}^{-1}(\nu \mathrm{C}-\mathrm{H})$, while the characteristic absorption peak of the azido group are located at 2115 $\mathrm{cm}^{-1}$ and $1739 \mathrm{~cm}^{-1}(\nu \mathrm{C}=\mathrm{O})$, and the peaks at 1652 and 1547 $\mathrm{cm}^{-1}$ are ascribed to the amide $\mathrm{I}$ band $(\nu \mathrm{C}=\mathrm{O})$ and amide II band $(\nu \mathrm{N}-\mathrm{H})$. The successful conjugation is evidenced by the fact that the characteristic azide absorbance peak at $2105 \mathrm{~cm}^{-1}$ disappeared in both spectra of $\mathrm{PCL}_{37}-\mathrm{SS}-\mathrm{PGluLac}_{10}$ and $\mathrm{PCL}_{37^{-}}$ SS-PGluGal ${ }_{10}$, respectively, when compared with that of $\mathrm{PCL}_{37^{-}}$ SS-PAELG ${ }_{10}$. The characteristic absorption peak of the ester group at $1739 \mathrm{~cm}^{-1}$ from the PCL segment appears in the FTIR spectrum. Furthermore, the absorbance peak at $3400 \mathrm{~cm}^{-1}$ belongs to the hydroxy group of the galactosyl and lactosyl sugar units, which confirmed the click conjugation reaction. Taken together, both the FTIR and ${ }^{1} \mathrm{H}$ NMR results confirmed the successful synthesis of the disulfide-bonds-linked PCL-SS-glycopolypeptides diblock copolymers. 


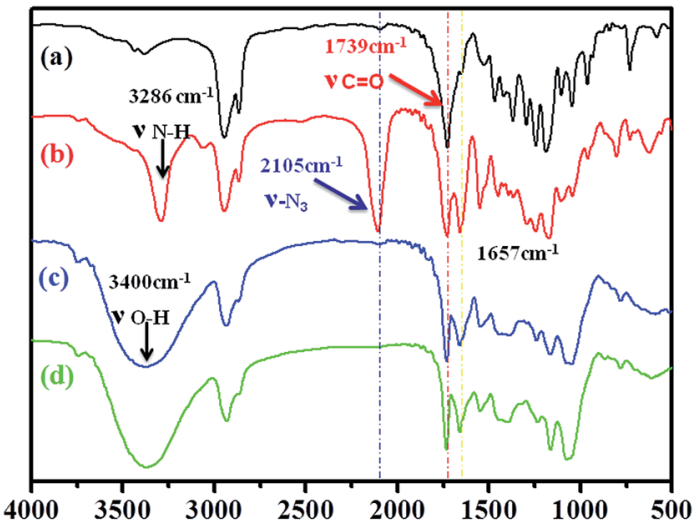

\section{Wavenumber $\left(\mathrm{cm}^{-1}\right)$}

Fig. 2 FTIR spectra of $P \mathrm{PC}_{37}-\mathrm{SS}-\mathrm{NH}_{2}$ (a), $\mathrm{PCL}_{37}-\mathrm{SS}-\mathrm{PAELG_{10 }}$ (b), $\mathrm{PCL}_{37}$-SS-PGluLac 10 (c), and $\mathrm{PCL}_{37}-\mathrm{SS}-\mathrm{PGluGal}_{10}$ (d).

\subsection{Micelles formation and their properties}

To evaluate the self-assembly of PCL-SS-GPPs diblock copolymers, the PCL-SS-GPPs micelles were prepared via the dialysis method. In this study, the self-assembly behavior in aqueous medium was investigated by using fluorometry in the presence of pyrene as a fluorescent probe, according to the method of Chen $e t a l .{ }^{42}$ It has been demonstrated that the variation in the intensity ratio $\left(I_{337} / I_{335}\right)$ of the vibronic peak at $337 \mathrm{~nm}$ to the vibronic peak at $335 \mathrm{~nm}$ is quite sensitive to the polarity of the microenvironment where pyrene is located. The ratio of $I_{337} / I_{335}$ as a function of the concentration of the PCL-SS-GPPs micelles is shown in Fig. 3. It is shown that at lower micelles concentrations, the $I_{337} / I_{335}$ values remain nearly unchanged. As the micelles concentrations increase, the intensity ratio starts to increase, implying the formation of micellar self-aggregates with hydrophobic domains. The critical micelle concentration (CMC) could be determined by the crossover point of two straight lines, as indicated in Fig. 3. The CMC values for $\mathrm{PCL}_{37^{-}}$ SS-PGluLac ${ }_{10}$ was about $0.0166 \mathrm{mg} \mathrm{mL}^{-1}$, which was higher than the value of $0.0105 \mathrm{mg} \mathrm{mL}^{-1}$ for $\mathrm{PCL}_{37}-\mathrm{SS}_{-} \mathrm{PGluGal}_{10}$. In our experiment, the sugars were highly effectively grafted onto the same $\mathrm{PCL}_{37}-\mathrm{SS}-\mathrm{PAELG}_{10}$. The lactose unit was more hydrophilic than the galactose unit, hence with a similar grafting efficiency, $\mathrm{PCL}_{37}-\mathrm{SS} \mathrm{PGluLac}_{10}$ was more hydrophilic than $\mathrm{PCL}_{37}-\mathrm{SS}-\mathrm{PGluGal}_{10}$, resulting in a higher $\mathrm{CMC}$ value. The CMC results of our experiment are similar to the previous results reported by Lecommandoux et al. ${ }^{34}$

Amphiphilic copolymers that can form reduction-sensitive micelles have attracted extensive attention for the active intracellular delivery of anticancer drugs and diagnostic agents. In this paper, the anticancer drug doxorubicin (DOX) and superparamagnetic iron oxide (SPIO) nanoparticles (NPs), as model therapeutic cargos and magnetic resonance imaging (MRI) contrast agents respectively, were simultaneously encapsulated in the hydrophobic core of the micelles by the dialysis method. The autocorrelation functions obtained from DLS measurements were analyzed using CONTIN analysis and were performed at a scattering angle varying from $40^{\circ}$ to $130^{\circ}$. In Fig. 4 , the dependence of the decay frequency, $\Gamma$, as a function of the square of the scattering vector $q^{2}$ ( $q$ is defined as $q=4 \pi n \sin (\theta)$ $2) / \lambda$, where $n$ is the refractive index of the solution, $q$ is the

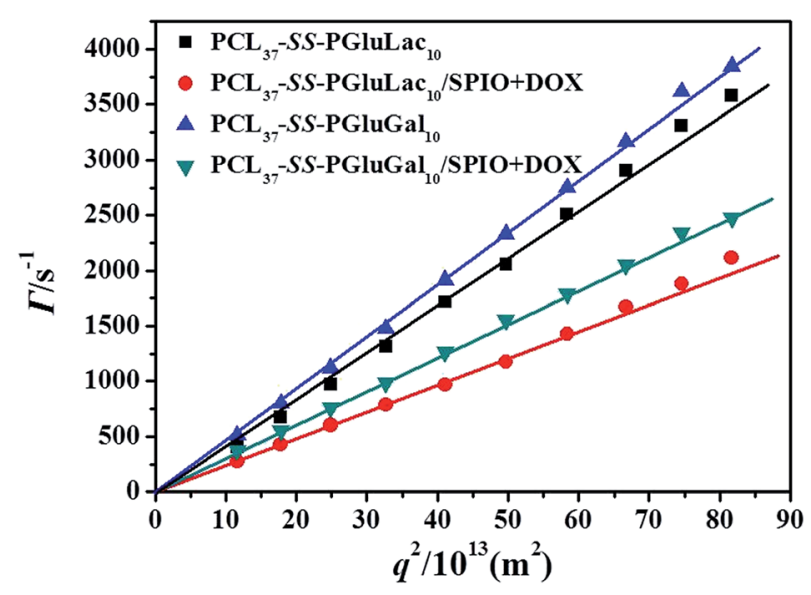

Fig. 4 Variation of decay rate vs. squared vector for aqueous systems of the blank and DOX/SPIO-CO-loaded PCL-SS-GPPs micelles at the test angles ranging from $50^{\circ}$ to $130^{\circ}$.
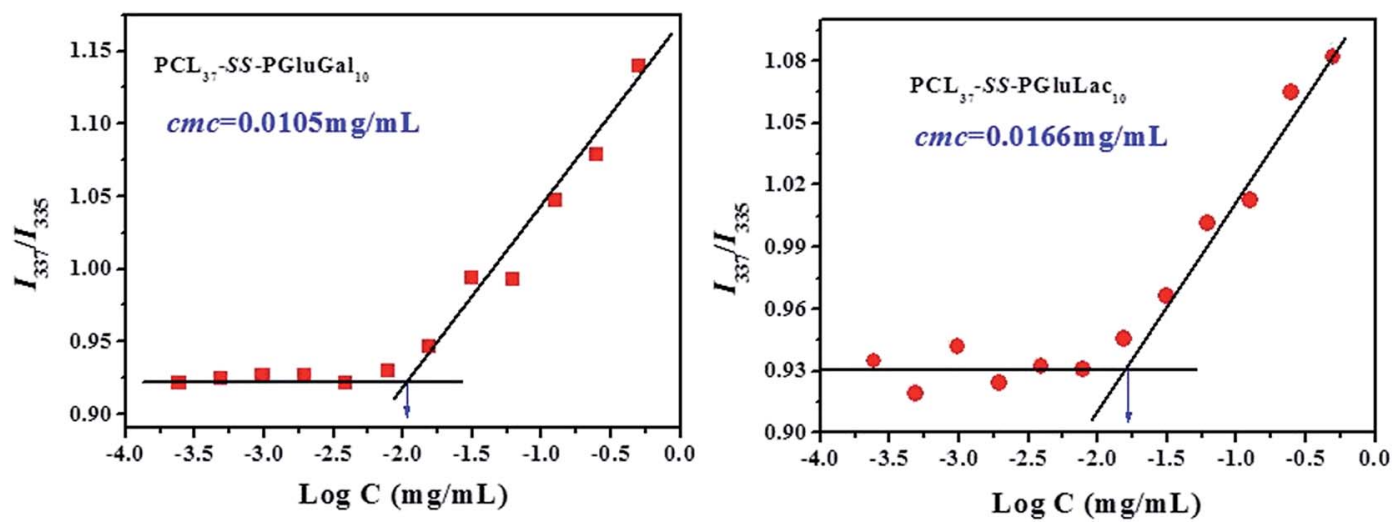

Fig. 3 Change in $I_{337} / /_{335}$ with the concentration of the PCL-SS-GPPs micelles. 
scattering angle, and $\lambda=632.8 \mathrm{~nm}$ is the wavelength of the incident laser light) was plotted. The linear variation of the relaxation frequency versus the squared scattering vector $q^{2}$ passing through the origin is the hallmark of a translational diffusive process, confirming the presence of spherical objects with a pure diffusive mode. ${ }^{34,43}$ According to the multi-angle DLS analyses results, we could conclude that the PCL-SSGPPs self-assembled in aqueous solution to form spherical micelles. Furthermore, for the SPIO and DOX-co-loaded PCLSS-GPPs micelles, the linear variation of the relaxation frequency versus the squared scattering vector $q^{2}$ passed through the origin too. Therefore, the PCL-SS-GPPs micelles still kept their the spherical form of the PCL-SS-GPPs micelles is well maintained in aqueous solution even after loading with SPIO and DOX.

The hydrodynamic diameters of the resulting micelles were obtained by DLS analysis. As shown in Fig. 5a, the mean diameter (MD) for the empty $\mathrm{PCL}_{37}-\mathrm{SS}-\mathrm{PGluGal}_{10}$ micellar aggregates was about $95.6 \mathrm{~nm}$. TEM studies were performed to reveal the morphology of the micellar aggregates. Sphericallike aggregates were found in the TME observations (Fig. 5c), which is in good agreement with the multi-angle DLS analysis results. DLS and TEM measurements were also applied to determine the mean diameter and the morphology of the DOX/ SPIO-loaded PCL $_{37}-\mathrm{SS}-\mathrm{PGluGal}_{10}$ micelles. Dynamic light scattering (DLS) measurements (Fig. 5c) showed that the mean diameter was $120.8 \mathrm{~nm}$ for DOX/SPIO-loaded $\mathrm{PCL}_{37}-\mathrm{SS}-$ PGluGal $_{10}$ micelles. The mean diameter of the empty and the DOX/SPIO-loaded PCL $_{37}-$ SS-PGluLac 10 was also determined by DLS (Table 1). The TEM image of the DOX/SPIO-loaded PCL $_{37}$-SS-PGluGal 10 micelles (Fig. 5d) shows that they are uniform in shape and have uniform size distribution. From Table 1, we find that compared to the empty PCL-SS-GPPs micelles, the SPIO and DOX-co-loaded micelles shown a bigger size. The increase in micelle sizes might be due to the hydrophobic DOX and SPIO being encapsulated into the hydrophobic core of the micelles.

\subsection{Bioactivity assay}

The bioactivity of the pendant galactosyl units in the PCL-SSGPPs diblock copolymers were assessed by carbohydrate-lectin binding experiments. It has been reported that lectin would specifically and selectively bind to galactosyl groups. ${ }^{44}$ In order to observe the binding interaction between lectin and the galactosyl residues more directly, we chose lectin conjugated with FITC (LEC-FITC) for the binding study. The PCL-SS-GPPS films were prepared and treated with LEC-FITC solution and then the films were imaged with an inverted fluorescence microscope (Fig. 6). Green fluorescence due to the FITC-labeled LEC was observed from the PCL-SS-GPPs films, while no fluorescence was observed from the PCL-SS-GPPs films without treatment with LEC-FITC. Furthermore, the binding assay of the PCL-SS-GPPs films with FITC and PCL-SS-PAELG films with LEC-FITC were carried out. As displayed in Fig. $\mathrm{S} 1, \uparrow$ these films did not exhibit green fluorescence as compared to the PCL-SSGPPs/LEC-FITC. The binding results indicated that the glycopolypeptides can bind specifically to the lectin. ${ }^{45}$
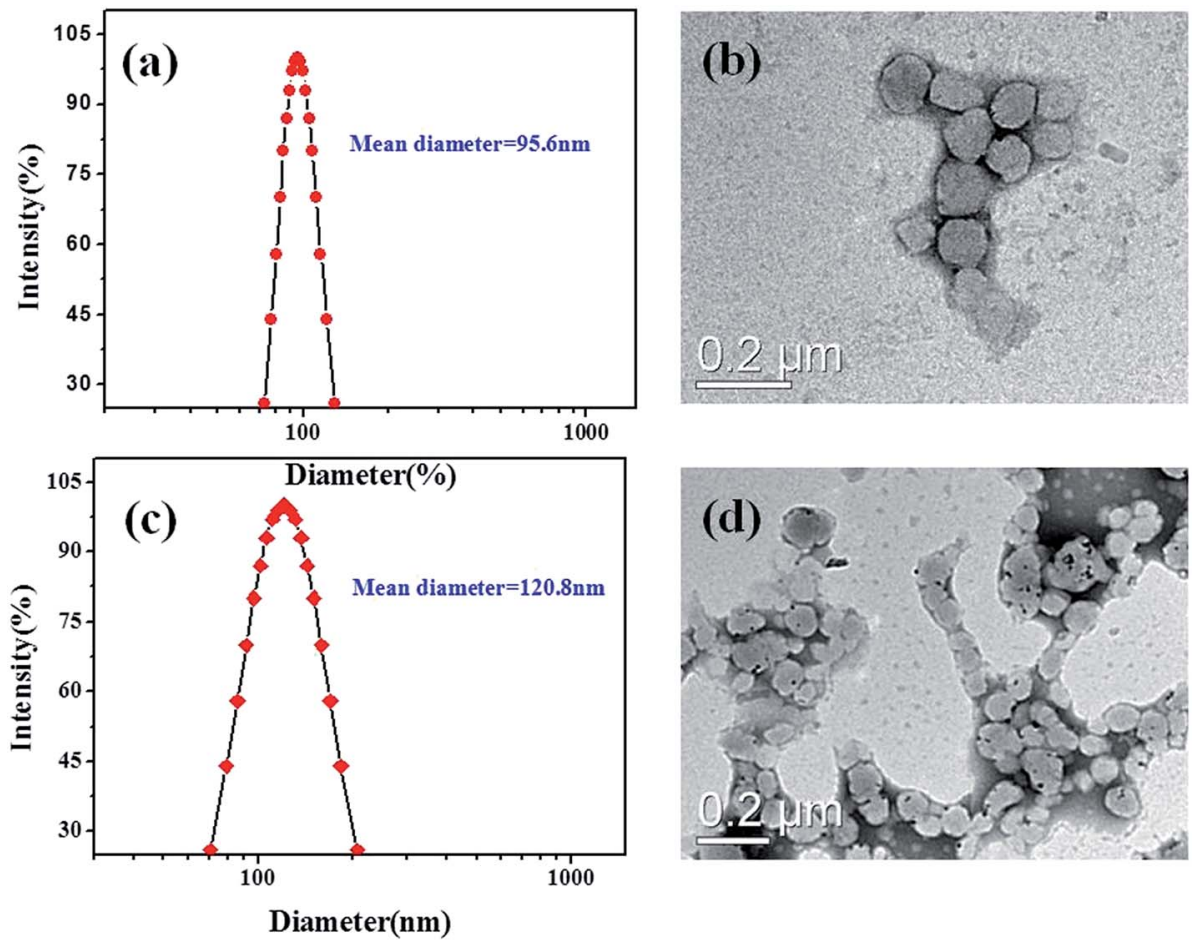

Fig. 5 Typical particle size distribution (a) and TEM image (b) of the blank $\mathrm{PCL}_{37}-\mathrm{SS}-\mathrm{PGluGal_{10 }}$ micelles; particle size distribution (c) and TEM image (d) of the DOX/SPIO-loaded PCL $37-S S-P G l u G a l_{10}$ micelles. 
Table 1 Characteristics of the blank and DOX/SPIO-loaded micelles ${ }^{a}$

\begin{tabular}{|c|c|c|c|c|c|c|c|}
\hline Sample code & \multicolumn{3}{|l|}{ Blank micelles } & \multicolumn{4}{|c|}{ DOX/SPIO-loaded micelles } \\
\hline PCL $_{37}-$ SS-PGluLac 10 & $102.4 \pm 0.7$ & $0.19 \pm 0.02$ & 0.0116 & $150.1 \pm 2.6$ & $0.15 \pm 0.03$ & 10.2 & 11.3 \\
\hline
\end{tabular}

${ }^{a}$ All the aggregate solutions had a final polymer concentration of $0.50 \mathrm{mg} \mathrm{mL}{ }^{-1} \cdot{ }^{b}$ Measured by dynamic light scattering (DLS). ${ }^{c}$ Determined by pyrene-based fluorescent spectrometry.
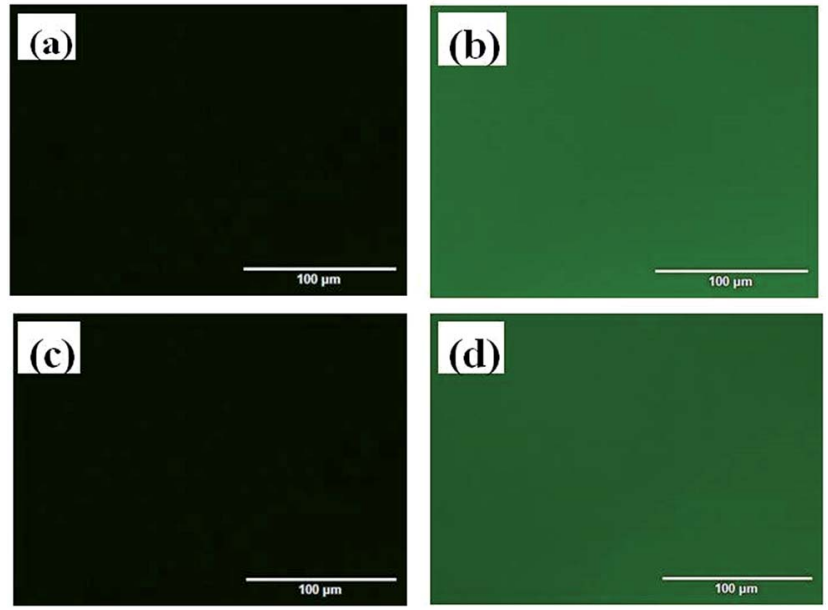

Fig. 6 Inverted fluorescence microscope images of cast films of $\mathrm{PCL}_{37}-\mathrm{SS}-\mathrm{PGluGal_{10 }}$ (a), PCL $37-\mathrm{SS}-\mathrm{PGluGal}_{10} / \mathrm{LEC}-\mathrm{FITC}$ (b), $\mathrm{PCL}_{37}-$ SS-PGluLac 10 (c), and PCL $37-S S-P G l u L a C_{10} /$ LEC-FITC (d)

\subsection{In vitro stimuli-responsive drug release}

Recently, reduction-sensitive nanocarriers have attracted much interest for active intracellular cargo release due to a high GSH concentration in cancer cells. ${ }^{46}$ DOX was loaded into the nanocarriers, and the release behavior of the loaded DOX from the PCL-SS-GPPs micelles without and with the exposure to GSH was evaluated in PBS at $\mathrm{pH}$ 7.4, as shown in Fig. 7. In the

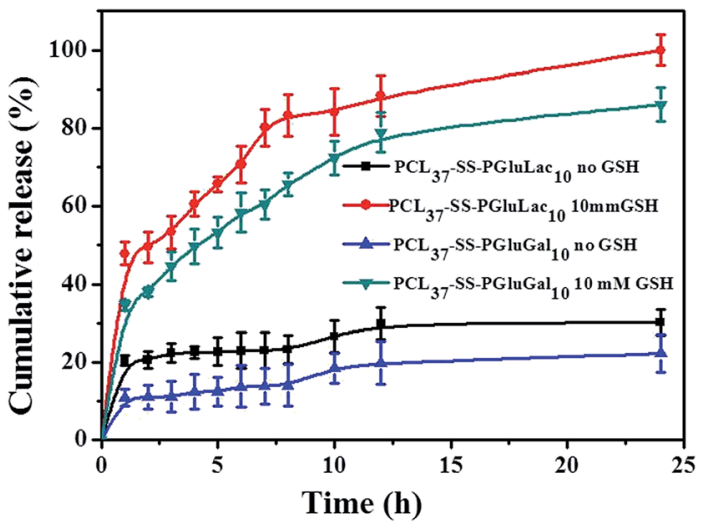

Fig. 7 The in vitro release behavior of loaded DOX from PCL-SSglycopolypeptides micelles in the absence and presence of GSH $\left(37^{\circ} \mathrm{C}, \mathrm{pH} 7.4\right)$. case of without GSH, the DOX/SPIO-loaded micelles showed a sustained and slow release. For instance, only about $22 \%$ and $35 \%$ of the DOX were released in $24 \mathrm{~h}$ from the $\mathrm{PCL}_{37}-\mathrm{SS}-$ PGluLac ${ }_{10}$ and $\mathrm{PCL}_{37}-\mathrm{SS}-\mathrm{PGluGal}_{10}$ micelles, respectively. In contrast, when $10 \mathrm{mM}$ GSH was employed to trigger the release of DOX, a concentration that was similar to the intracellular GSH concentration, the DOX/SPIO-loaded micelles showed a burst release, in which $58.36 \%$ and $70.66 \%$ of the DOX was released in the initial $6 \mathrm{~h}$. The amount of DOX release reached $81 \%$ and complete release was observed within $24 \mathrm{~h}$. According to the above release results, the rapid release of DOX could be attributed to the cleavage of disulfide linkages by GSH consistent with results observed by Zhong and co-workers. ${ }^{\mathbf{4 6 4} 7}$ This reduction control release behavior is of particular interest in achieving tumor-targeted DOX delivery. It is expected that the loaded drug will remain in the nanocarriers during the circulation time in the bloodstream, where the concentration of GSH is about $2 \mu \mathrm{M}$. After the vesicles are taken up by the cells into their cytoplasm where the GSH is about 1-10 mM, faster DOX release occurs once the disulfide bonds are cleaved by the GSH (Fig. 7).

\subsection{In vitro cell cytotoxicity and cellular uptake}

MTT assay was performed to investigate the in vitro cytotoxicity of the blank PCL-SS-GPPs micelles toward HepG2 cell lines. The cells were incubated with PCL-SS-GPPs micelles at various concentrations for $48 \mathrm{~h}$. The in vitro cell proliferation assay

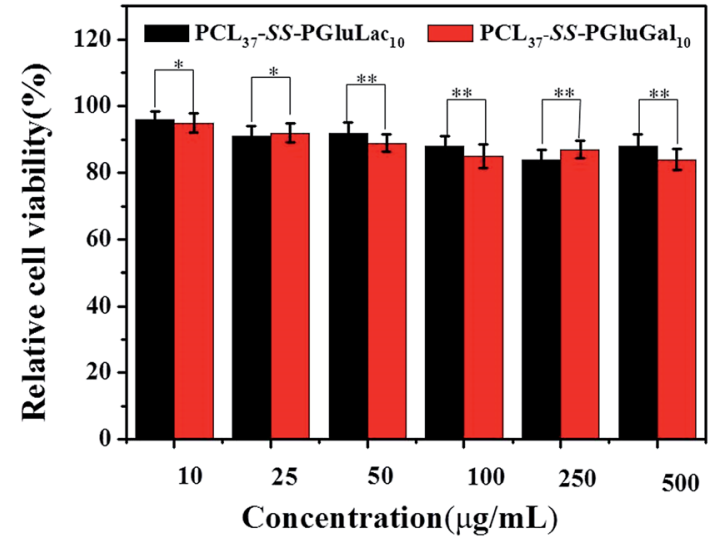

Fig. 8 In vitro cytotoxicity studies of blank PCL-SS-GPPs micelles against HepG2 cells lines at different concentrations after $48 \mathrm{~h}$ incubation period $(* p<0.05, * * p<0.01)$. 
revealed that the viabilities of the HepG2 cells were over $80 \%$, even with the PCL-SS-GPPs micelles concentrations up to 500 $\mu \mathrm{g} \mathrm{mL}^{-1}$, confirming that these biodegradable PCL-SS-GPPs micelles have excellent biocompatibility (Fig. 8).

To demonstrate the potential antitumor utility of the PCLSS-GPPs micelles, the use of HepG2 cell lines was employed to investigate the cytotoxicity of the DOX/SPIO-loaded $\mathrm{PCL}_{37}-\mathrm{SS}-$ PGluGal $_{10}$ and PCL $_{37}-$ SS-PGluLac 10 micelles, with free DOX tested as a positive control. HepG2 cells were treated with free DOX and DOX/SPIO-loaded micelles with various equivalent DOX concentrations from 0.01 to $10 \mu \mathrm{g} \mathrm{mL}^{-1}$. After incubation for $48 \mathrm{~h}$, the cell viability was evaluated by MTT assay. From the MTT assay results, we could conclude that the viability of HepG2 cells was mainly dependent on the DOX concentrations. As the DOX concentrations increased, the viability of the HepG2 cells incubated with both free DOX and DOX/SPIO-loaded micelles decreased. Furthermore, compared to the DOX loaded into the micelles, the free DOX showed the highest cytotoxicity against the HepG2 cells, regardless of the DOX concentration. DOX is a widely used anticancer drug, but direct administration of DOX can induce many side-effects, such as cardiotoxicity. ${ }^{48}$ Consequently, DOX is loaded into micelles, which not only prolongs the release profiles, it gives higher therapeutic effects and reduced side-effects. ${ }^{49}$ Previous studies revealed that galactose ligand exhibits high specificity to asialoglycoprotein receptor (ASGP-R)-overexpressing hepatoma cells, including HepG2 cells. ${ }^{50}$ PCL-SS-GPPs micelles containing galactose or a lactose pendent unit can act as multifunction nanocarriers with the ability to target the ASGP-Roverexpressing hepatoma cells and to then release the antitumor drugs under the reduction microenvironment of the hepatoma cells (Fig. 9).

The fluorescence signal of DOX allows us to follow their internalization and intracellular distribution by using fluorescence microscopy and flow cytometry. For the fluorescence microscopy analysis, the HepG2 cells lines were incubated with free DOX and DOX/SPIO-loaded micelles for $4 \mathrm{~h}$ at a DOX concentration of $10 \mu \mathrm{g} \mathrm{mL}^{-1}$. As shown in Fig. 10, strong DOX

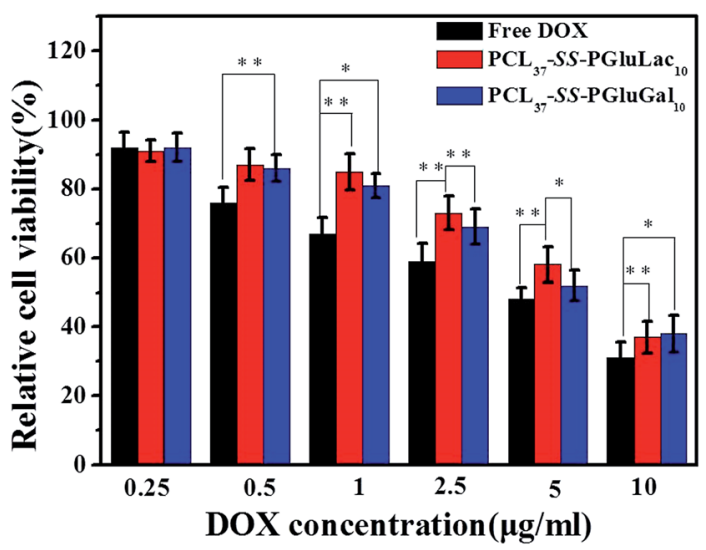

Fig. 9 Cytotoxicity of the free DOX, DOX/SPIO-loaded $\mathrm{PCL}_{37}-\mathrm{SS}-$ PGluGal ${ }_{10}$, and $\mathrm{PCL}_{37}-\mathrm{SS}-\mathrm{PGluLac}_{10}$ micelles against HepG2 cells at different DOX concentrations (incubation time 48 h) $(* p<0.05, * * p<$ 0.01).
(A)

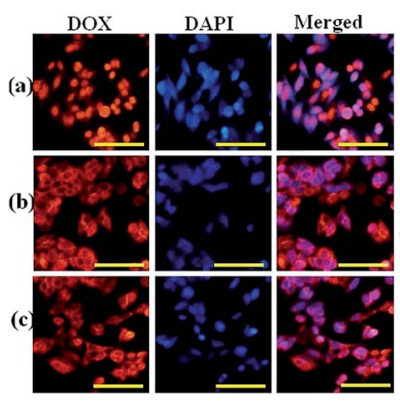

(B)

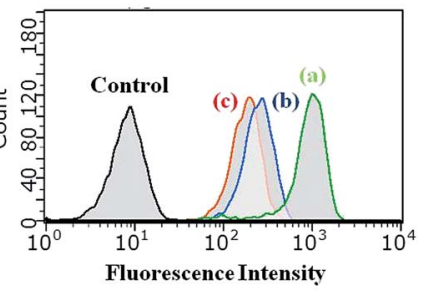

Fig. 10 (A) Fluorescence microscope images of HepG2 cells incubated with free DOX (a), DOX/SPIO-loaded PCL ${ }_{37}-\mathrm{SS}-\mathrm{PGluLac}_{10}$ (b), and DOX/SPIO-loaded $\mathrm{PCL}_{37}-\mathrm{SS}-\mathrm{PGluGa}_{10}$ micelles (c) for $4 \mathrm{~h}$ at $37{ }^{\circ} \mathrm{C}$. Scale bars represent $200 \mu \mathrm{m}$ in all the images. (B) Flow cytometry plots for the control, free DOX (a), DOX/SPIO-loaded $\mathrm{PCL}_{37}$-SS-PGluGal 10 micelles (b), and DOX/SPIO-loaded $\mathrm{PCL}_{37}-\mathrm{SS}-$ PGluLac 10 micelles (c) in HepG2 cell lines at $37^{\circ} \mathrm{C}$ for $4 \mathrm{~h}$, as measured by flow cytometry.

fluorescence appeared in the perinuclear as well as in the nuclear regions of the cells, possibly due to the fast internalization of DOX inside the cells and intercalation of the chromosomal DNA. It should be noted that the HepG2 cells incubated with free DOX showed higher DOX fluorescence intensity than those incubated with DOX-loaded micelles. By merging the fluorescence microscopy pictures of DOX and DAPI, we found that free DOX mainly accumulated in the cell nucleus, whereas for the DOX delivered by PCL-SS-glycopolypeptides micelles, the DOX fluorescence mainly appeared in the cytoplasm and only partly in the cell nucleus. It has been reported that free DOX transported into cells occurs through a passive diffusion mechanism, while DOX-loaded micelles are internalized in the cells by an endocytosis mechanism. ${ }^{\mathbf{4 9 , 5 1}}$ Hence, the PCL-SS-glycopolypeptides micelles could act as an efficient vehicle to transport DOX into the cytoplasm via an endocytic pathway.

Flow cytometry was used for quantitative determination of the DOX levels in HepG2 cells. From the flow cytometry analysis results, we found that the highest fluorescence intensity was observed in the HepG2 cells incubated with free DOX, compared to the cells incubated with DOX-loaded micelles for $4 \mathrm{~h}$, which was consistent with the cellular uptake behavior observed by fluorescence microscopy and this could be attributed to the different cellular uptake mechanisms. Moreover, HepG2 cells treated with DOX-loaded PCL $_{37}-\mathrm{SS}-\mathrm{PGluGal}_{10}$ micelles had a higher DOX level than those treated with $\mathrm{PCL}_{37^{-}}$ SS-PGluLac 10 micelles.

In order to reveal the hepatocyte-targeting ability of the obtained PCL-SS-GPPs, a galactose competitive inhibition assay was performed. Invert fluorescence microscopy analysis (Fig. S2 $\dagger$ ) showed the red fluorescence of DOX in the HepG2 cells. The HepG2 cells without pretreatment with galactose showed the strongest red fluorescence, as compared to the pretreated galactose HepG2 cells. Furthermore, flow cytometry analysis (Fig. S3 $\dagger$ ) was carried to quantify the fluorescence intensity. The flow cytometry analysis results revealed that as 


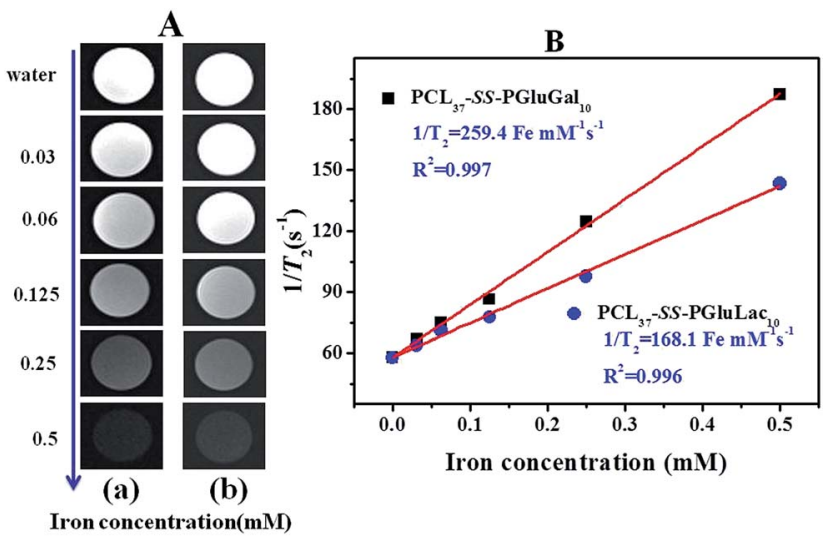

Fig. 11 (A) $T_{2}$-Weighted MRI images of the DOX/SPIO-loaded $\mathrm{PCL}_{37}-$ SS-PGluGal 10 micelles (a) and $\mathrm{PCL}_{37}-\mathrm{SS}-\mathrm{PGluLac} 10$ micelles (b). (B) Relaxation rates $\left(\mathrm{s}^{-1}\right)$ of $T_{2}$ as a function of iron concentration $(\mathrm{mM})$ for the DOX/SPIO-loaded PCL $37-S S-$ PGluGal $_{10}$ and $\mathrm{PCL}_{37}-\mathrm{SS}-$ PGluLac 10 micelles.

the galactose concentration increased from $0,10,50$, to $100 \mathrm{mM}$, the DOX fluorescence intensity decreased from 167.62, 101.16 , 89.40, to 75.37 , respectively.

SPIO nanoparticles are capable of shortening the transverse relaxation time of water protons and their net effectiveness is expressed by $T_{2}$ relaxivity $\left(r_{2}\right)$, which represents the reciprocal of the relaxation time per unit concentration of metal ions. ${ }^{52}$ In vitro MRI experiments were carried out in a 3.0T Siemens MRI scanner at room temperature. $T_{2}$-Weighted images of the DOX/ SPIO-loaded PCL-SS-GPPs micelles at various iron concentrations are shown in Fig. 11A, a remarkable darkening appeared with the increasing concentration of micelles. Fig. 11B displays the $T_{2}$ rates of SPIO/DOX-loaded micelles over iron concentrations. The $T_{2}$ relaxivity increased dramatically with iron concentration. Relaxivity can be calculated through the linear least-squares fitting of 1 /relaxation time $\left(\mathrm{s}^{-1}\right)$ versus the iron concentration (mM Fe). According to our measurements, we noted a steeper slope in Fig. 11B for PCL $_{37}-$ SS-PGluGal $10\left(r_{2}=\right.$ 259.4 Fe m M$\left.{ }^{-1} \mathrm{~s}^{-1}\right)$ as compared to $\mathrm{PCL}_{37}-$ SS-PGluLac ${ }_{10}\left(r_{2}=\right.$ 168.1 $\mathrm{Fe} \mathrm{mM}^{-1} \mathrm{~s}^{-1}$ ). The $r_{2}$ value of the SPIO-loaded particles was affected by many factors, such as particle size, magnetic field, compositions of the SPIO nanocrystals, and the degree of SPIO clustering..$^{53}$ Loading the SPIO into the hydrophobic inner core shortens the distant of each SPIO and leads to an increase of $r_{2}$. SPIO/DOX-loaded PCL $_{37}-\mathrm{SS}-\mathrm{PGluGal}_{10}$ micelles thus showed a smaller size, hence they had higher $r_{2}$ values as compared to SPIO/DOX-loaded PCL $_{37}-\mathrm{SS}-\mathrm{PGluLac}_{10}$ micelles. The $r_{2}$ values for the DOX/SPIO-loaded PCL-SS-GPPs micelles were also larger than for Feridex® $\left(111.5 \mathrm{Fe} \mathrm{mM}^{-1} \mathrm{~s}^{-1}\right)$, a commercially available SPIO-based MRI contrast agent widely used in clinical MRI (Fig. 11). ${ }^{54}$

\section{Conclusion}

In this work, disulfide-bonds-linked PCL-SS-GPPs polymers were synthesized. The PCL-SS-GPPs, including $\mathrm{PCL}_{37}-\mathrm{SS}-$ PGluGal $_{10}$ and $\mathrm{PCL}_{37}-\mathrm{SS}-\mathrm{PGluLac}_{10}$, formed stable nano-sized micelles in an aqueous medium. The binding tests showed a specific recognition between the sugars on the surface of the PCL-SS-GPPs films with the FITC-labeled lectin. Furthermore, the $T_{2}$ contrast agent hydrophobic superparamagnetic $\mathrm{Fe}_{3} \mathrm{O}_{4}$ and the anticancer drug doxorubicin were simultaneously loaded into the hydrophobic inner cores of the micelles. The DOX/SPIO-loaded micelles exhibited rapid drug release behavior in response to the intracellular level of reducing potential (10 mM GSH). MTT results of the DOX-loaded micelles showed an obvious proliferation inhibition effect on HepG2 tumor cells. Fluorescence images and flow cytometry tests revealed that DOX could be efficiently transported into HepG2 tumor cells by PCL-SS-GPPs micelles. The SPIO-loaded micelles showed increased MRI sensitivity and relaxivity. Consequently, these reduction-sensitive amphiphilic PCL-SS-GPPs showed significant potential as theranostic nanocarriers for $\mathrm{MR}$ imaging and chemotherapy.

\section{Acknowledgements}

This work was supported by the National Natural Science Foundation of China (81571665), the Natural Science Foundation of Guangdong Province (2014A030313647), the Science and Technology Plan Foundation of Guangzhou (201510010263, 1563000477, 201510010086, 201607010038), the Social Development Fund of Guangdong Province (2014A020212031). The authors thank Nian-Hua Wang for her assistance in data processing.

\section{References}

1 D. T. Leong and K. W. Ng, Adv. Drug Delivery Rev., 2014, 79, 95-106.

2 K. Riehemann, S. W. Schneider, T. A. Luger, B. Godin, M. Ferrari and H. Fuchs, Angew. Chem., 2009, 48, 872-897.

3 R. K. Jain and T. Stylianopoulos, Nat. Rev. Clin. Oncol., 2010, 7, 653-664.

4 S. R. Croy and G. S. Kwon, Curr. Pharm. Des., 2006, 12, 46694684.

5 N. Nishiyama and K. Kataoka, Pharmacol. Ther., 2006, 112, 630-648.

6 A. Zhang, Z. Zhang, F. Shi, J. Ding, C. Xiao, X. Zhuang, C. He, L. Chen and X. Chen, Soft Matter, 2013, 9, 2224-2233.

7 X. Zhang, J. Chen, Z. Luo, D. Wu, X. Shen, S. Song, Y. Sun, P. Liu, J. Zhao and S. Huo, Adv. Healthcare Mater., 2013, 3, 133-141.

8 X. Yang, Y. Chen, R. Yuan, G. Chen, E. Blanco, J. Gao and X. Shuai, Polymer, 2008, 49, 3477-3485.

9 X. Wang, Y. Yang, Y. Zhuang, P. Gao, F. Yang, H. Shen, H. Guo and D. Wu, Biomacromolecules, 2016, 17, 2920-2929.

10 M. Prabaharan, J. J. Grailer, S. Pilla, D. A. Steeber and S. Gong, Biomaterials, 2009, 30, 6065-6075.

11 X. Yang, J. J. Grailer, I. J. Rowland, A. Javadi, S. A. Hurley, D. A. Steeber and S. Gong, Biomaterials, 2010, 31, 9065-9073.

12 J. Kim, Y. Piao and T. Hyeon, Chem. Soc. Rev., 2009, 38, 372390. 
13 N. Song, M. Ding, Z. Pan, J. Li, L. Zhou, H. Tan and Q. Fu, Biomacromolecules, 2013, 14, 4407-4419.

14 L. Y. Rizzo, B. Theek, G. Storm, F. Kiessling and T. Lammers, Curr. Opin. Biotechnol., 2013, 24, 1159-1166.

15 W. Wang, D. Cheng, F. Gong, X. Miao and X. Shuai, Adv. Mater., 2012, 24, 115-120.

16 U. Y. Lee, Y. T. Oh, D. Kim and E. S. Lee, Int. J. Pharm., 2014, 471, 166-172.

17 W. Chen, Y. Zou, J. Jia, F. Meng, R. Cheng, C. Deng, J. Feijen and Z. Zhong, Macromolecules, 2013, 46, 699-707.

18 Z. Ma, Y. Hong, D. M. Nelson, J. E. Pichamuthu, C. E. Leeson and W. R. Wagner, Biomacromolecules, 2011, 12, 3265-3274.

19 P. Ma, S. Liu, Y. Huang, X. Chen, L. Zhang and X. Jing, Biomaterials, 2010, 31, 2646-2654.

20 W. Chen, Y. Zou, F. Meng, R. Cheng, C. Deng, J. Feijen and Z. Zhong, Biomacromolecules, 2014, 15, 900-907.

21 D. Pati, A. Y. Shaikh, S. Das, P. K. Nareddy, M. J. Swamy, S. Hotha and S. S. Gupta, Biomacromolecules, 2012, 13, 1287-1295.

22 D. Ponader, P. Maffre, J. Aretz, D. Pussak, N. M. Ninnemann, S. Schmidt, P. H. Seeberger, C. Rademacher, G. U. Nienhaus and L. Hartmann, J. Am. Chem. Soc., 2014, 136, 2008-2016.

23 J. R. Kramer and T. J. Deming, Polym. Chem., 2013, 5, 671682.

24 K. Upadhyay, J. F. L. Meins, A. Misra, P. Voisin, V. Bouchaud, E. Ibarboure, C. Schatz and S. Lecommandoux, Biomacromolecules, 2009, 10, 2802-2808.

25 C. Schatz, S. Louguet, J. L. Meins and S. Lecommandoux, Angew. Chem., 2009, 48, 2572-2575.

26 J. R. Kramer, A. R. Rodriguez, U. Choe, D. T. Kamei and T. J. Deming, Soft Matter, 2013, 9, 3389-3395.

27 J. Huang and A. Heise, Chem. Soc. Rev., 2013, 42, 7373-7390.

28 A. C. Engler, H. Lee and P. T. Hammond, Angew. Chem., 2009, 48, 9334-9338.

29 C. Bonduelle and S. Lecommandoux, Biomacromolecules, 2013, 14, 2973-2983.

30 T. J. Deming, Chem. Rev., 2016, 116, 786-808.

31 C. Xiao, C. Zhao, P. He, Z. Tang, X. Chen and X. Jing, Macromol. Rapid Commun., 2010, 31, 991-997.

32 H. Tang and D. Zhang, Biomacromolecules, 2010, 11, 15851592.

33 K. Krannig, J. Sun and H. Schlaad, Biomacromolecules, 2014, 15, 978-984.

34 C. Gauche and S. Lecommandoux, Polymer, 2016, 107, 474484.

35 J. Huang, C. Bonduelle, J. Thevenot, S. Lecommandoux and A. Heise, J. Am. Chem. Soc., 2012, 134, 119-122.
36 N. Hadjichristidis, H. Iatrou, M. Pitsikalis and G. Sakellariou, Chem. Rev., 2009, 109, 5528-5578.

37 D. Pati, S. Das, N. G. Patil, N. Parekh, D. H. Anjum, V. Dhaware, A. V. Ambade and S. S. Gupta, Biomacromolecules, 2016, 17, 466-475.

38 Z. Wang, R. Sheng, T. Luo, J. Sun and A. Cao, Polym. Chem., 2017, 8, 472-484.

39 H.-K. Yang, M. Qi, L. Mo, R.-M. Yang, X.-D. Xu, J.-F. Bao, W.-J. Tang, J.-T. Lin, L.-M. Zhang and X.-Q. Jiang, RSC Adv., 2016, 6, 114519-114531.

40 T. Borase, T. Ninjbadgar, A. Kapetanakis, S. Roche, R. Oconnor, C. Kerskens, A. Heise and D. F. Brougham, Angew. Chem., 2013, 52, 3164-3167.

41 X. Jiang, J. Liu, L. Xu and R. Zhuo, Macromol. Chem. Phys., 2011, 212, 64-71.

42 S. Yu, C. He, J. Ding, Y. Cheng, W. Song, X. Zhuang and X. Chen, Soft Matter, 2013, 9, 2637-2645.

$43 \mathrm{~J}$. Rodriguezhernandez, J. Babin, B. Zappone and S. Lecommandoux, Biomacromolecules, 2005, 6, 2213-2220.

44 R. Mildner and H. Menzel, Biomacromolecules, 2014, 15, 4528-4533.

45 S. Das, D. Pati, N. Tiwari, A. Nisal and S. S. Gupta, Biomacromolecules, 2012, 13, 3695-3702.

46 H. Sun, B. Guo, X. Li, R. Cheng, F. Meng, H. Liu and Z. Zhong, Biomacromolecules, 2010, 11, 848-854.

47 Y. Zhong, W. Yang, H. Sun, R. Cheng, F. Meng, C. Deng and Z. Zhong, Biomacromolecules, 2013, 14, 3723-3730.

48 S. Turakhia, C. D. Venkatakrishnan, K. Dunsmore, H. R. Wong, P. Kuppusamy, J. L. Zweier and G. Ilangovan, Am. J. Physiol.: Heart Circ. Physiol., 2007, 293, H3111-H3121.

49 K. K. Upadhyay, A. N. Bhatt, A. K. Mishra, B. S. Dwarakanath, S. Jain, C. Schatz, J.-F. Le Meins, A. Farooque, G. Chandraiah, A. K. Jain, A. Misra and S. Lecommandoux, Biomaterials, 2010, 31, 2882-2892.

50 X. Wang, H. Sun, F. Meng, R. Cheng, C. Deng and Z. Zhong, Biomacromolecules, 2013, 14, 2873-2882.

51 X. Shuai, H. Ai, N. Nasongkla, S. Kim and J. Gao, J. Controlled Release, 2004, 98, 415-426.

52 H. Su, Y. Liu, D. Wang, C. Wu, C. Xia, Q. Gong, B. Song and H. Ai, Biomaterials, 2013, 34, 1193-1203.

53 J. Lu, S. Ma, J. Sun, C. Xia, C. Liu, Z. Wang, X. Zhao, F. Gao, Q. Gong and B. Song, Biomaterials, 2009, 30, 2919-2928.

54 X. Yang, J. J. Grailer, I. J. Rowland, A. Javadi, S. A. Hurley, V. Z. Matson, D. A. Steeber and S. Gong, ACS Nano, 2010, 4, 6805-6817. 